\title{
ESTIMATIVA DE RECURSOS, UTILIZANDO O MÉTODO DE KRIGAGEM ORDINÁRIA, PARA O DEPÓSITO DE TERRAS RARAS ÁREA ZERO, ARAXÁ (MG)
}

\author{
RESOURCE ESTIMATION THROUGH ORDINARY KRIGING FOR AREA ZERO REE DEPOSIT, \\ ARAXÁ $(M G)$
}

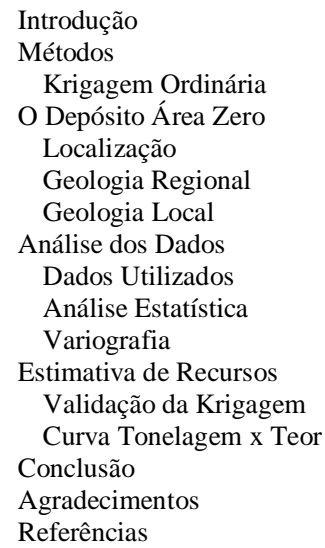

Adriano Santos Delgado de OLIVEIRA; Washington Barbosa LEITE JÚNIOR

Universidade Estadual Paulista. Instituto de Geociências e Ciências Exatas. Avenida 24-A, 1.515. Rio Claro - SP. E-mails: adriano_delgado@hotmail.com; w.leite@ unesp.br

RESUMO - O depósito de elementos terras raras (ETR) Área Zero localiza-se no município de Araxá, Minas Gerais. Situa-se na porção sul da Faixa Brasília, na Província Ígnea do Alto Paranaíba, inserido no Complexo Alcalino-Carbonatítico do Barreiro. O complexo é uma intrusão circular, com aproximadamente $16 \mathrm{~km}^{2}$ de área. Apresenta-se como uma estrutura dômica e a mineralização é resultado do enriquecimento supergênico das rochas carbonatíticas, ricas em ETR. A área de estudos encontra-se na porção norte do complexo, em uma área de 400×200 m. O objetivo do trabalho foi quantificação dos recursos através do método de krigagem ordinária, utilizando dados de 61 furos de sondagem diamantada. Análises estatísticas mostraram que o depósito possui uma grande variabilidade de teores. Para executar a krigagem ordinária, o modelo esférico foi ajustado para os variogramas experimentais direcionais. A variografia indicou que a direção de maior continuidade do depósito foi a de 22,5/0 com amplitude de $51 \mathrm{~m}$. O modelo de blocos foi construído com as dimensões 10x10x3 m respeitando o contato entre as unidades. Todas as unidades estão mineralizadas e os recursos do depósito totalizam 10,5 milhões de toneladas com teor médio de 4,75\% de óxidos totais de terras raras.

Palavras-chave: Geologia. Métodos estatísticos. Elementos terras raras. Krigagem ordinária. Estimativa de recursos.

\begin{abstract}
The "Área Zero" deposit is located in the municipality of Araxá, Minas Gerais. It is located in the southern portion of the Brasilia Belt, in the Igneous Province of Alto Paranaíba, inserted in the Barreiro Alkaline-Carbonatitic Complex. The complex is a circular intrusion with approximately $16 \mathrm{~km}^{2}$. It is a dome structure and mineralization is a result of the supergene enrichment of carbonatitic rocks, with high levels of rare earth elements (REE). The study area is located in the northern portion of the complex, in an area of 400x200 m. This study aimed to estimate the resources through ordinary kriging method, using a database from 61 boreholes. Statistical analyses showed a great variability of REE grades. To carry out ordinary kriging, a spherical model was fitted over experimental directional variograms. Plotting experimental variograms in different directions showed that the direction of greater continuity was $22,5 / 0$ and $51 \mathrm{~m}$ range. To estimate the REE grade, a block model was built with dimensions of $10 \times 10 \times 3 \mathrm{~m}$ to estimate resources by units. All the units present in the deposit area are mineralized and the resources of Area Zero deposit totaled 10,5 million tonnes with $4,75 \%$ of REE content.
\end{abstract}

Keywords: Geology. Statistic method. Rare Earth elements. Ordinary kriging. Resource estimate.

\section{INTRODUÇÃO}

Os elementos terras raras (ETR) constituem um grupo de 17 elementos químicos, sendo 15 elementos da série dos lantanídeos: Lantânio (La), Cério (Ce), Praseodímio (Pr), Neodímio $(\mathrm{Nd})$, Promécio $(\mathrm{Pm})$, Samário $(\mathrm{Sm})$, Európio $(\mathrm{Eu})$, Gadolíneo $(\mathrm{Gd})$, Térbio $(\mathrm{Tb})$, Disprósio (Dy), Hólmio (Hm), Érbio (Er), Túlio (Tm), Itérbio ( $\mathrm{Yb}$ ) e Lutécio ( $\mathrm{Lu})$, somados ao
Escândio (Sc) e Ítrio (Y) por apresentarem propriedades físico-químicas semelhantes (Voncken, 2016).

Os ETR podem ser divididos em leves (La, $\mathrm{Ce}, \mathrm{Pr}, \mathrm{Nd}, \mathrm{Pm}$ e $\mathrm{Sm}$ ) e pesados (Gd, Tb, Dy, Hm, Er, Tm, Yb e Lu). O Y insere-se nos pesados, já o Eu pode ser incluído nos dois grupos, mesmo apresentando características distintas dos outros 
ETR. Os ETR são elementos estratégicos que possuem amplo uso na indústria de alta tecnologia e, apesar de ocorrerem numa variedade de espécies minerais, sua concentração em depósitos econômicos são relativamente raros.

Nesse contexto, encontra-se o depósito "Área Zero", localizado no município de Araxá, MG, que possui sua mineralização conhecida desde a década de 60 , porém novos dados de sondagem foram obtidos entre 2011 e 2012 com o objetivo de reavaliar a sua potencialidade econômica.

$\mathrm{O}$ uso de ferramentas geoestatísticas para análises quantitativas de recursos minerais tem sido amplamente utilizado nos últimos anos. $\mathrm{O}$ avanço dessa ciência possibilitou um maior entendimento dos depósitos minerais, sendo utilizada para prever o comportamento de variáveis de interesse em locais ainda não amostrados. Desse modo, a geoestatística vem sendo utilizada a fim de reduzir as incertezas nas modelagens, aumentando o nível de conhecimento geológico com teores e valores de tonelagem próximo ao real, permitindo assim, a viabilização do empreendimento mineiro.

A Krigagem Ordinária é a técnica mais utilizada para avaliação de recursos minerais, sendo conhecida pelo acrônimo B.L.U.E. (best linear unbiased estimation): linear porque a estimativa é uma combinação linear das amostras vizinhas, unbiased (não viciada) porque busca o resíduo médio ou valor do erro igual a zero e best (melhor) porque minimiza a variância de estimativa dos erros (Isaaks \& Srivastava,1989).

Esse artigo, resultado de uma dissertação de mestrado, apresenta a estimativa de recursos para o depósito de ETR Área Zero, utilizando um modelo de blocos com as dimensões de $10 \mathrm{~m} \mathrm{x}$ $10 \mathrm{~m} \times 3 \mathrm{~m}$.

\section{MÉTODOS}

\section{Krigagem Ordinária}

De acordo com Yamamoto (2001), a krigagem é um método que permite estimar o valor desconhecido $Z^{*}\left(x_{0}\right)$ associado a um ponto, área ou volume a partir de um conjunto $n$ de dados $\left\{Z\left(x_{i}\right), i=1, n\right\}$ disponíveis.

$\mathrm{O}$ estimador da krigagem ordinária $Z^{*}{ }_{K O}\left(x_{0}\right)$ pode ser obtido através da seguinte equação:

$$
Z^{*}{ }_{K O}\left(x_{0}\right)=\sum_{i=1}^{n} \lambda_{i} Z\left(x_{i}\right)
$$

$\lambda_{i}$ representam os pesos associados ao valor medido na posição $x_{i}$.

Os ponderadores $\left(\lambda_{i}, i=1, \ldots, n\right)$ são obtidos através da resolução de um sistema de equações lineares chamado de Equações de Krigagem. Journel \& Huijbregts (1978) estipulam que os ponderadores são calculados sob duas condições de restrição:

(i) que o estimador não seja enviesado, ou seja, tendencioso e;

(ii) que a variância de estimativa seja mínima.

O não viés da estimativa é obtido quando o erro (diferença entre valor real e valor calculado) é igual a zero:

$$
E\left[Z^{*}{ }_{K O}\left(X_{0}\right)-Z\left(X_{0}\right)\right]=0
$$

Desenvolvendo a expressão da esperança do erro, define-se a condição de não viés:

$$
\sum_{i=1}^{n} \lambda_{i}=1
$$

A variância da estimativa ou variância do erro de estimativa pode ser expressa de acordo com a seguinte equação:

$$
\sigma_{E}^{2}=\operatorname{Var}\left[Z\left(x_{0}\right)-Z^{*}{ }_{K O}\left(x_{0}\right)\right]
$$

A minimização da variância da estimativa, sujeita à condição de não enviesamento, resulta no sistema de equações de krigagem ordinária:

$$
\begin{gathered}
\sum_{j=1}^{n} \lambda_{j} C\left(x_{i}-x_{j}\right)-\mu=C\left(x_{i}-x_{0}\right) \text { para } i=1, n \\
\sum_{j=1}^{n} \lambda_{j}=1
\end{gathered}
$$

As equações também podem ser representadas em forma matricial:

$$
\left[\begin{array}{ccccc}
C\left(x_{1}-x_{1}\right) & C\left(x_{1}-x_{2}\right) & \ldots & C\left(x_{1}-x_{n}\right) & 1 \\
C\left(x_{2}-x_{1}\right) & C\left(x_{2}-x_{2}\right) & \ldots & C\left(x_{2}-x_{n}\right) & 1 \\
\vdots & \vdots & \ldots & \vdots & \vdots \\
C\left(x_{n}-x_{1}\right) & C\left(x_{n}-x_{2}\right) & \ldots & C\left(x_{n}-x_{n}\right) & 1 \\
1 & 1 & \ldots & 1 & 0
\end{array}\right]\left[\begin{array}{c}
\lambda_{1} \\
\lambda_{2} \\
\vdots \\
\lambda_{n} \\
-\mu
\end{array}\right]=\left[\begin{array}{c}
C\left(x_{0}-x_{1}\right) \\
C\left(x_{0}-x_{2}\right) \\
\vdots \\
C\left(x_{0}-x_{n}\right) \\
1
\end{array}\right]
$$

$C\left(x_{n}-x_{n}\right)$ representa a variância espacial entre amostras;

$C\left(x_{0}-x_{n}\right)$ representa a variância espacial entre amostras e ponto estimado e;

$\mu$ representa o multiplicador de Lagrange utilizado para obter a variância mínima sob a condição $\sum \lambda_{i}=1$. 


\section{O DEPÓSITO ÁREA ZERO}

\section{Localização}

O depósito Área Zero localiza-se no município de Araxá, inserido na macrorregião do Alto Paranaí- ba e mesorregião do Triângulo Mineiro do Estado de Minas Gerais (Figura 1). Dista 370 km da capital mineira (Belo Horizonte) e 590 km de São Paulo.

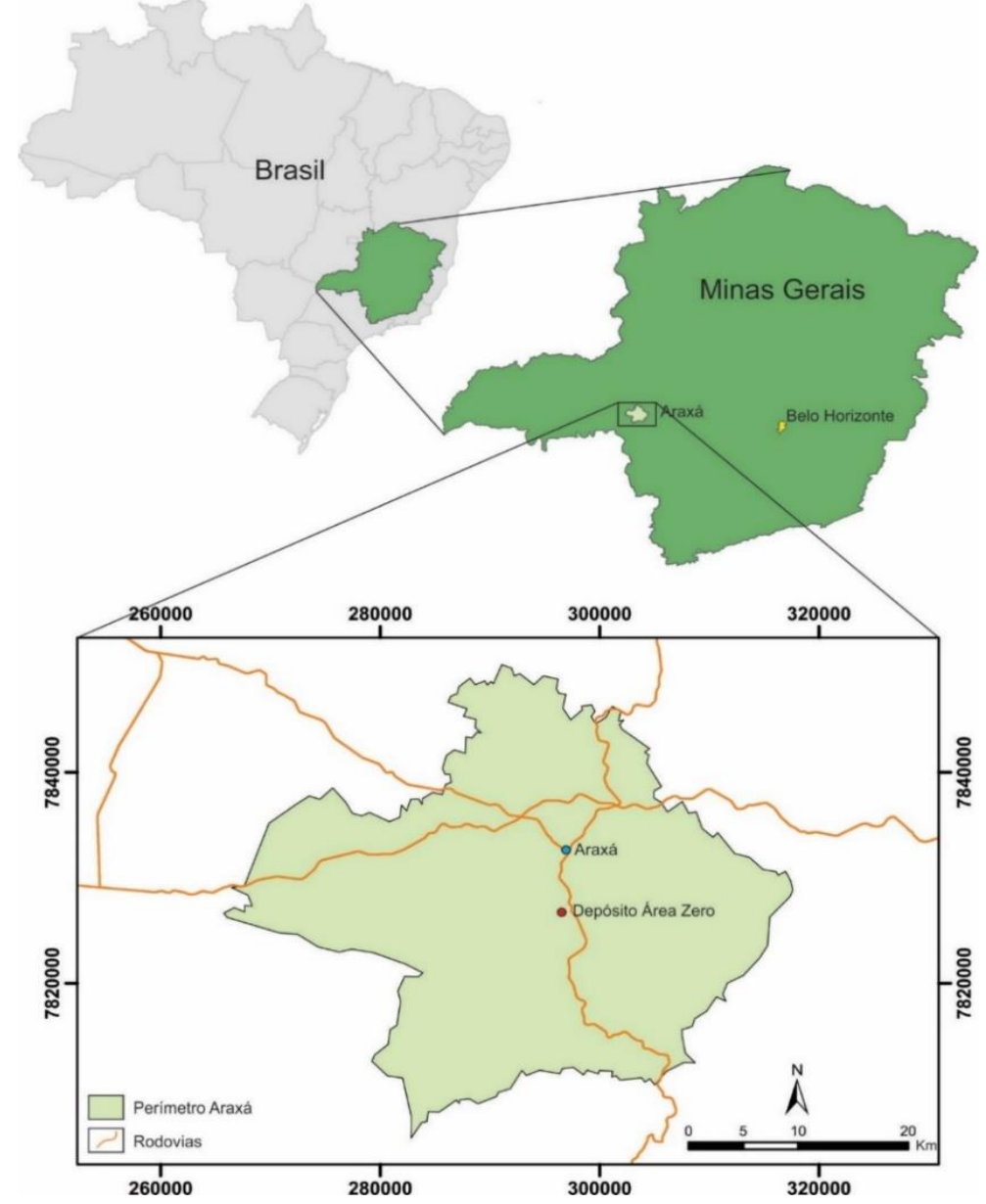

Figura 1 - Mapa de localização do município de Araxá em território Nacional e a posição do depósito em relação à área urbana do município.

\section{Geologia Regional}

O depósito Área Zero situa-se na porção sul da Faixa Brasília, na Província Ígnea do Alto Paranaíba (Figura 2), inserido no Complexo Alcalino-Carbonatítico Araxá, também conhecido como Complexo Alcalino-Carbonatítico do Barreiro (Traversa et al., 2001), um dos mais importantes complexos alcalino-carbonatíticos do mundo, o qual é hospedeiro da maior reserva mundial de nióbio.

O complexo é uma intrusão circular, com aproximadamente $4,5 \mathrm{~km}$ de diâmetro e $16 \mathrm{~km}^{2}$ de área. As rochas encaixantes são xistos e quartzitos do Grupo Ibiá (Figura 3) deformados em estrutura dômica (Seer, 1999). O complexo é constituído por carbonatitos, sustentando o núcleo, e por uma complexa rede de diques concêntricos e radiais, assim como pequenos veios com espessura variando de milímetros a centímetros. Os veios e diques estão presentes tanto no complexo alcalino quanto nas rochas hospedeiras.
Segundo Issa Filho et al. (1984) existe um halo de fenitização que atinge até $2,5 \mathrm{~km}$ de distância a partir do contato do carbonatito com a encaixante, resultando na formação de arfvedsonita, calcita, feldspato alcalino, piroxênio sódico e apatita nos quartzitos (especialmente nas fraturas). Gibson et al. (1995) concluíram que a atividade magmática alcalina ocorreu entre 80 e $90 \mathrm{Ma}$. As idades foram geradas a partir de análise de rochas e minerais através dos métodos $\mathrm{K} / \mathrm{Ar}$, $\mathrm{Ar} / \mathrm{Ar}$ e U/Pb.

O centro do complexo é composto por beforsitos e glimeritos, com sovítos subordinados. O núcleo é circundado por glimeritos com beforsitos associados. Ocorre uma zona de flogopitito metassomático entre o núcleo carbonatítico e a encaixante, como pode ser verificado na figura 4. Silva (1986) expressa que ao contrário dos outros complexos presentes na Província, o tipo de carbonatito predominante é o dolomítico, com sovitos (calcita carbonatitos) ocorrendo apenas na porção NW da intrusão. 


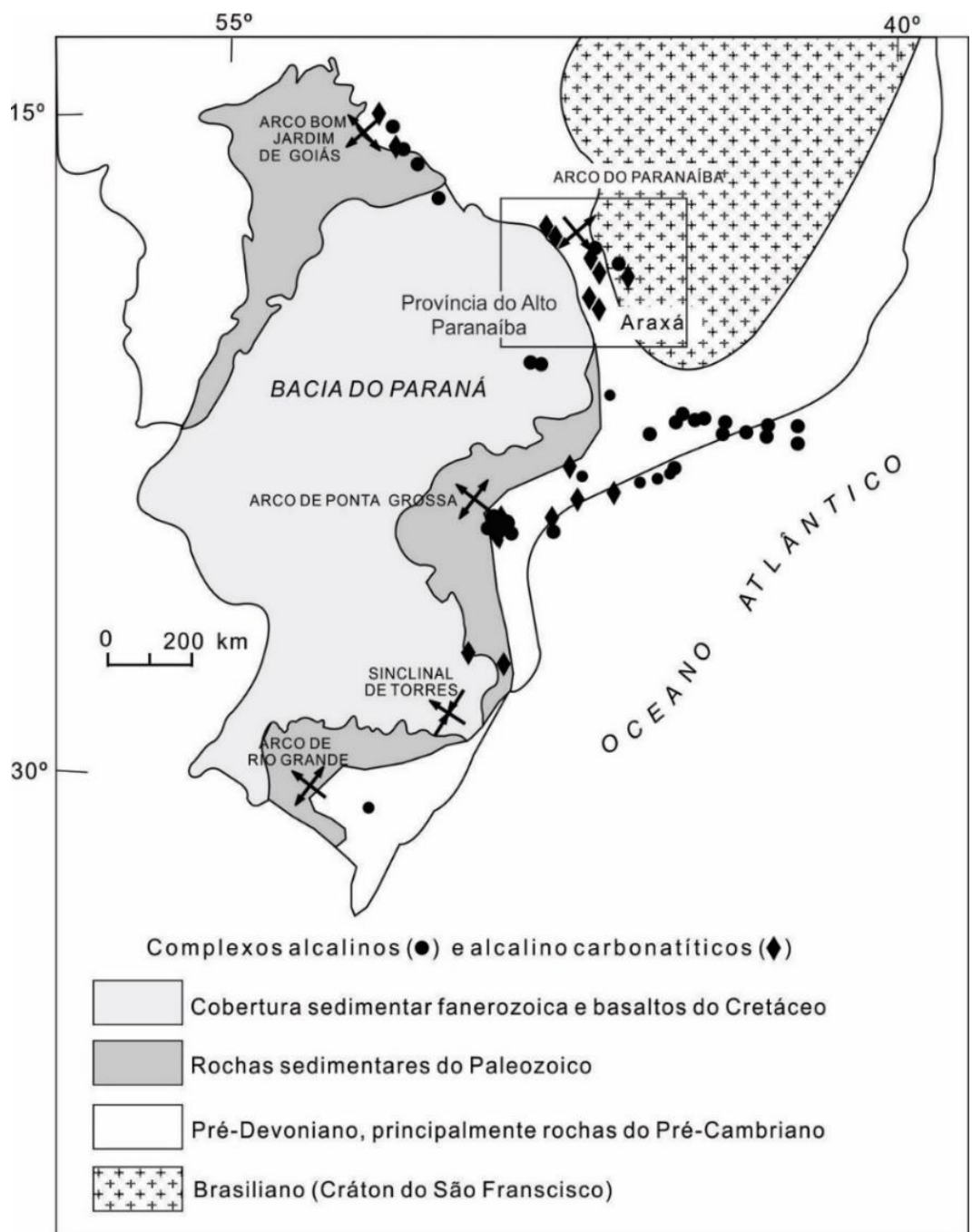

Figura 2 - Ocorrências de rochas alcalinas e alcalino-carbonatíticas na porção Sul do Brasil. A Província Ígnea do Alto Paranaíba está destacada. (Modificado de Traversa et al., 2001).

O centro do complexo é composto por beforsitos e glimeritos, com sovítos subordinados. O núcleo é circundado por glimeritos com beforsitos associados. Ocorre uma zona de flogopitito metassomático entre o núcleo carbonatítico e a encaixante, como pode ser verificado na figura 4. Silva (1986) expressa que ao contrário dos outros complexos presentes na Província, o tipo de carbonatito predominante é o dolomítico, com sovitos (calcita carbonatitos) ocorrendo apenas na porção NW da intrusão.

A erosão e o intemperismo dessas rochas alcalinas criaram um espesso perfil de alteração (atingindo até $230 \mathrm{~m}$ ), gerando uma concentração residual de determinados minerais $\mathrm{e}$ consequentemente o enriquecimento em nióbio, fosfato e ETR, dependendo da composição química predominante na rocha fonte.

\section{Geologia Local}

A área de estudos encontra-se na porção norte do complexo, em uma área de $400 \mathrm{~m}$ x $200 \mathrm{~m}$, com seu maior eixo orientado segundo a direção
E-W (Figura 4).

De acordo com informações extraídas de 67 furos de sondagem diamantada, Waring et al. (2013) definiram um empilhamento estratigráfico local, dividido em três grupos principais: superficial, eluvial e rocha sã. $O$ grupo superficial consiste nas unidades denominadas de solo, colúvio/alúvio, intervalo caulinítico e laterita. $\mathrm{O}$ grupo eluvial, também chamado de residual, é representado pela unidade saprolítica (carbonatito alterado) e por fim o terceiro grupo com apenas uma unidade, a rocha inalterada (carbonatito). A coluna estratigráfica esquemática local pode ser visualizada na figura 5 e a descrição das unidades, da base para o topo,conforme os autores supracitados, será apresentada a seguir:

- O carbonatito (rocha inalterada) apresenta coloração cinza e cinza esverdeado, com abundância de flogopita, além de estruturas e texturas diversas, sugerindo alteração hidrotermal. Carbonato dolomítico e pirita ocorrem como vênulas disseminadas na rocha; 


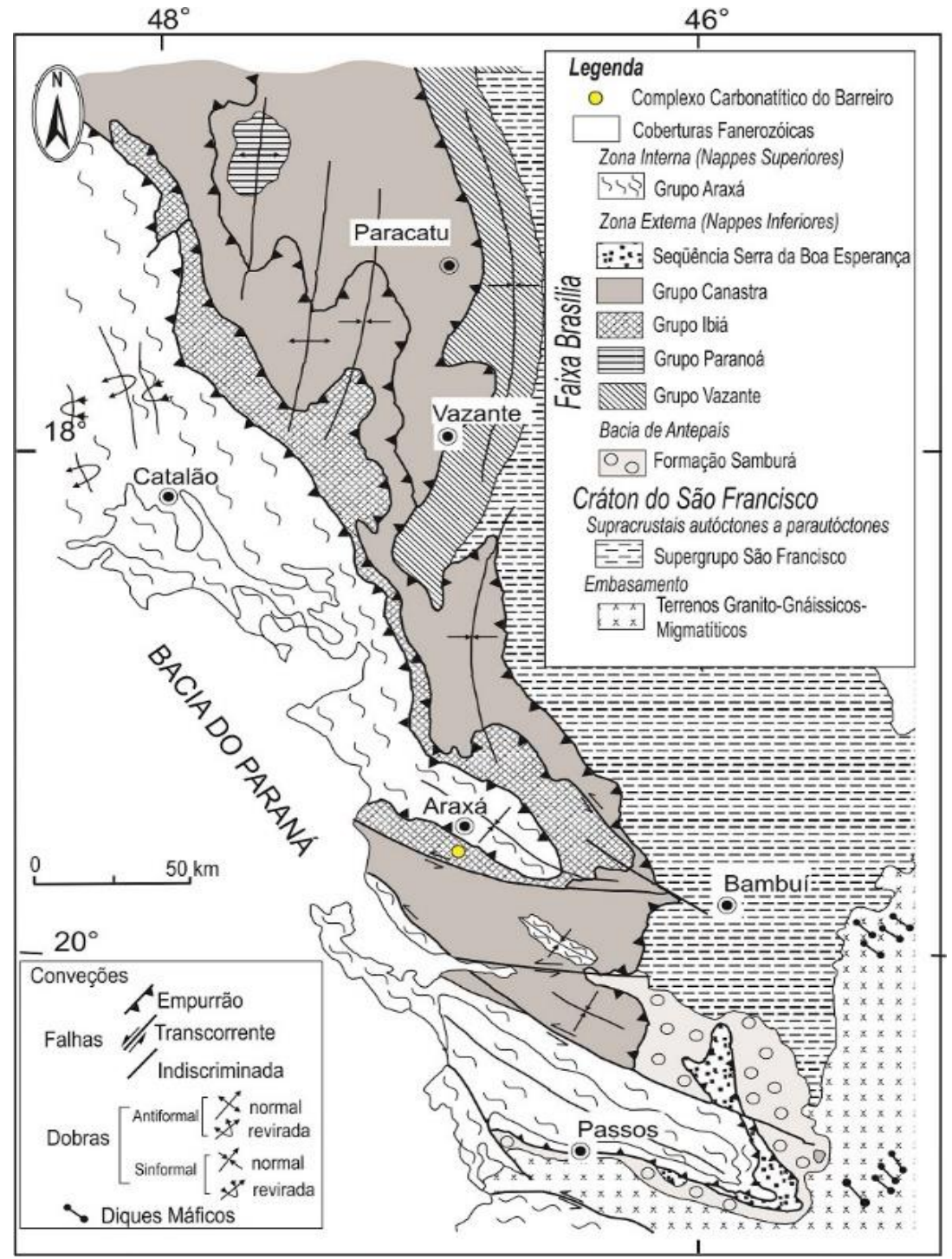

Figura 3 - Localização do Complexo Alcalino-Carbonatítico do Barreiro na Porção Sul da Faixa Brasília (Modificado de Silva et al., 2006).

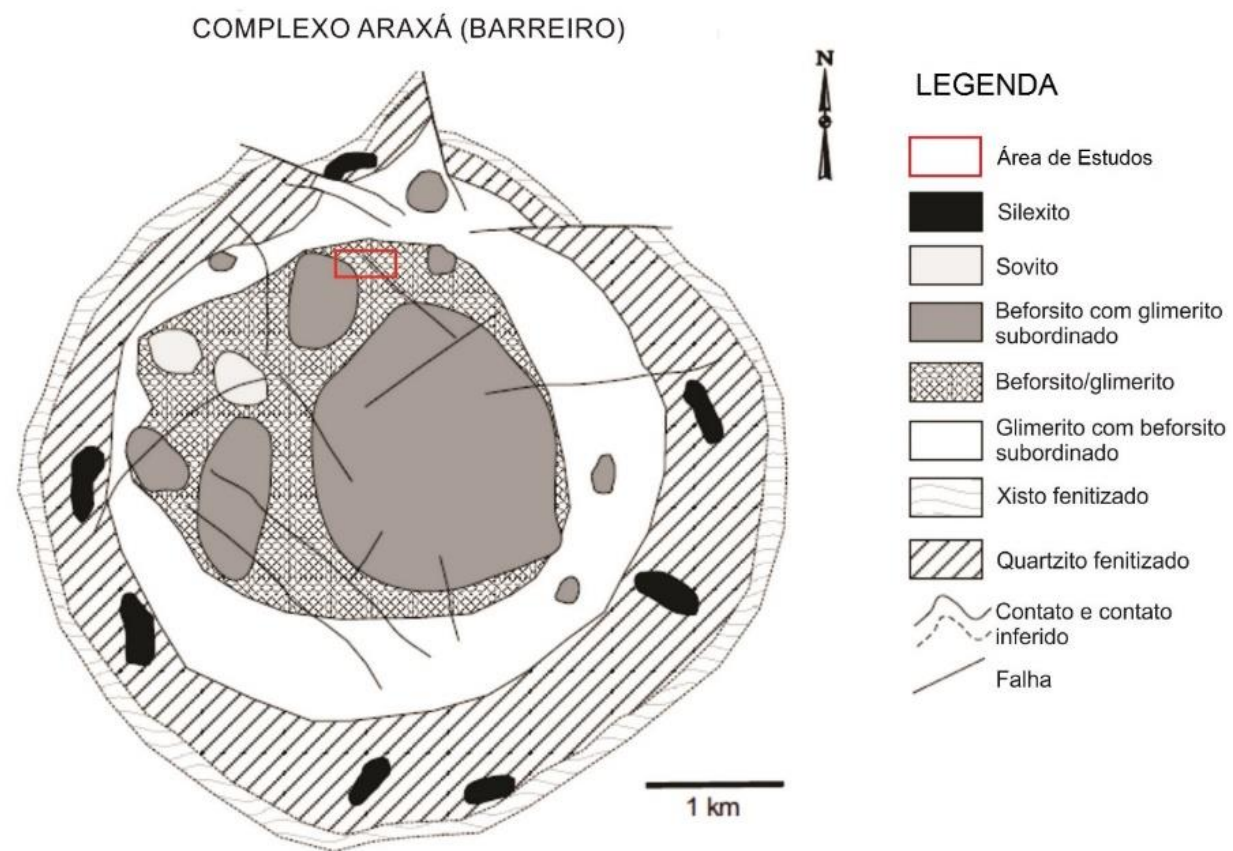

Figura 4 - Localização da área de estudos (depósito Área Zero) na interpretação geológica do Complexo AlcalinoCarbonatítico do Barreiro (Modificado de Traversa et al., 2001). 


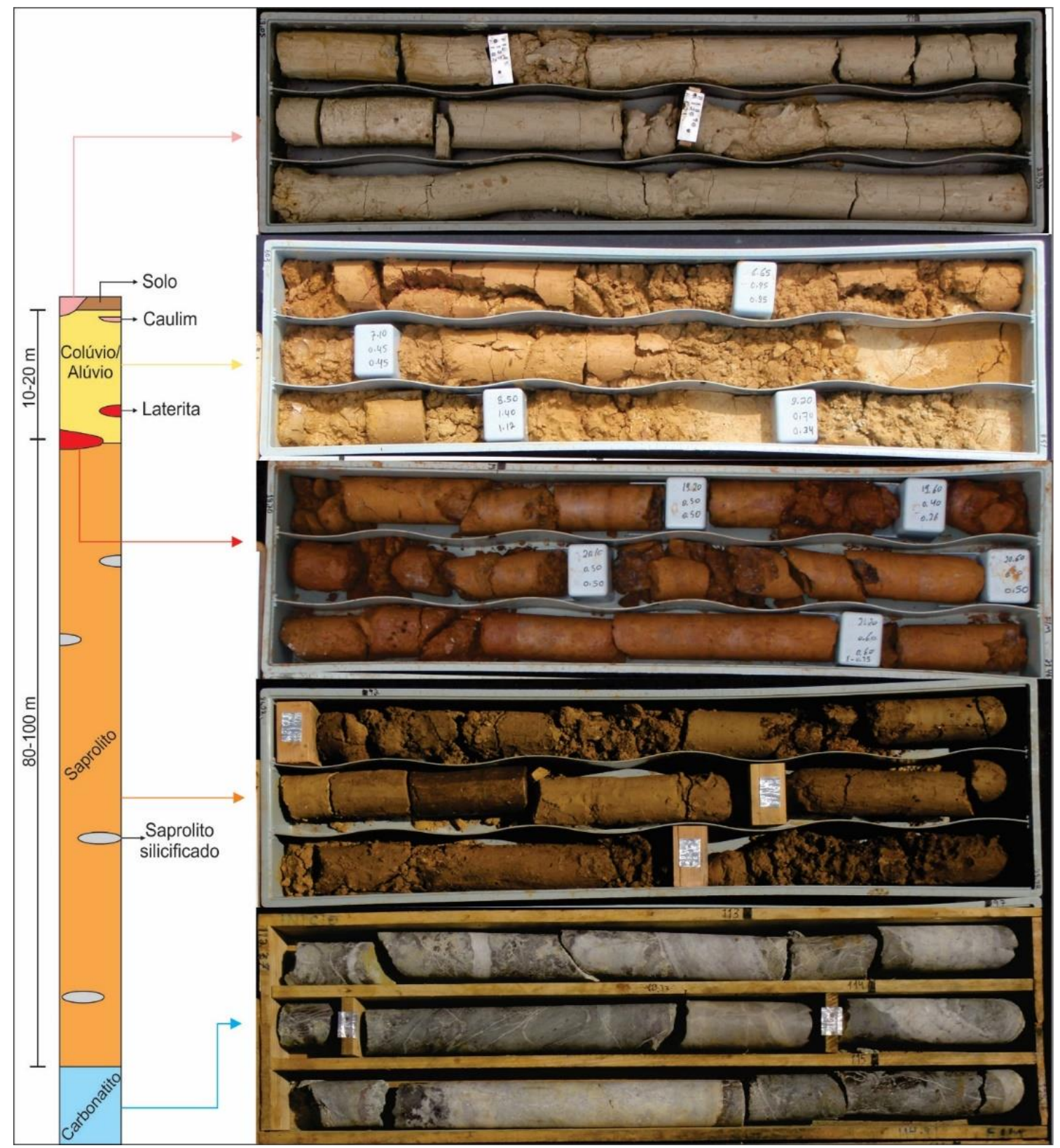

Figura 5 - Coluna estratigráfica esquemática da área do Depósito Zero, elaborada com base nos testemunhos de sondagem.

- O saprolito (carbonatito intemperizado) possui porções silicificadas, ferruginosas (goethita) e manganíferas. Zonas centimétricas com grãos subarredondados, fortemente fosfatizados são identificados nessa unidade, associado aos cristais de magnetita. Os sedimentos previamente descritos destacam-se do material saprolítico, com sua gênese atribuída a depósitos aluvionares desenvolvidos em drenagem subterrânea, gerado por lixiviação cárstica do carbonatito, em uma fase anterior à saprolitização;

- A unidade laterítica desenvolveu-se em ambiente superficial no topo da unidade saprolítica, e também pode ser encontrada intercalada com a unidade colúvio/alúvio.
Texturas primárias do carbonatito, assim como minerais contendo terras raras (monazita), podem ser identificados nessa unidade, assim como uma expressiva quantidade de óxido de manganês e;

- A unidade colúvio/alúvio possui aproximadamente $15 \mathrm{~m}$ de espessura. Sua gênese é atribuída ao material saprolítico, retrabalhado, transportado por gravidade e/ou corpo de água, com presença de sedimentos arenosos e argilosos oriundos das drenagens vizinhas. Consiste em intervalos de coloração amarelo e marrom claro, com uma matriz fina e grãos de quartzo, com granulação variando de fina a média. Localmente encontram-se partículas granulares de laterita. Intervalos cauliníticos ocorrem intercalados nessa unidade na forma de bolsões, apresentando 
até $12 \mathrm{~m}$ de espessura.

De acordo com Lapido-Loureiro \& Santos (2013) a mineralização é resultado do

O corpo enriquecido em ETR caracteriza-se pela horizontalidade dos níveis mineralizados, intercalando faixas mais ricas com outras mais pobres nesses elementos. A zona principal de enriquecimento situa-se entre a superfície e o nível freático. Os ETR encontram-se predominantemente na monazita (acima de 70\%) e também numa solução sólida dos minerais do enriquecimento supergênico de rochas carbonatíticas subjacentes, ricas em ETR.

grupo da plumbogummite, onde gorceixita predomina e cerianita e bastnaesita ocorrem em porções inferiores a $1 \%$ (Neumann \& Medeiros, 2015). Ainda segundo os autores, o nióbio $(\mathrm{Nb})$ ocorre nos minerais do supergrupo do pirocloro e o fosfato $\left(\mathrm{P}_{2} \mathrm{O}_{5}\right)$ atribuído à monazita bem como aos minerais do grupo da plumbogummite. Apatita ocorre em pequenas quantidades.

\section{ANÁLISE DOS DADOS}

\section{Dados Utilizados}

Foram utilizados dados de 61 furos de sondagem (Figura 6), fornecidos pela empresa MbAC Fertilizantes (atualmente Itafos) com informações de coordenadas e nomes dos furos, análises químicas do total de óxidos de terras raras (TREO - total of rare earth oxides) em porcentagem (com exceção do Sc), profundidade final, inclinação do furo, medidas de densidade, informações sobre as unidades (solo, colúvio/alúvio, caulim, laterita, saprolito e carbonatito) e a superfície do terreno.

\section{Análise Estatística}

A regularização das amostras foi efetuada utilizando o software Datamine ${ }^{\circledR}$ para que todas as amostras possuíssem o mesmo suporte. Para isso, o método down-the-hole foi utilizado. Esse tipo de regularização inicia-se na porção superior do furo (superfície), buscando padronizar um tamanho fixo de amostra, em direção ao final do furo.

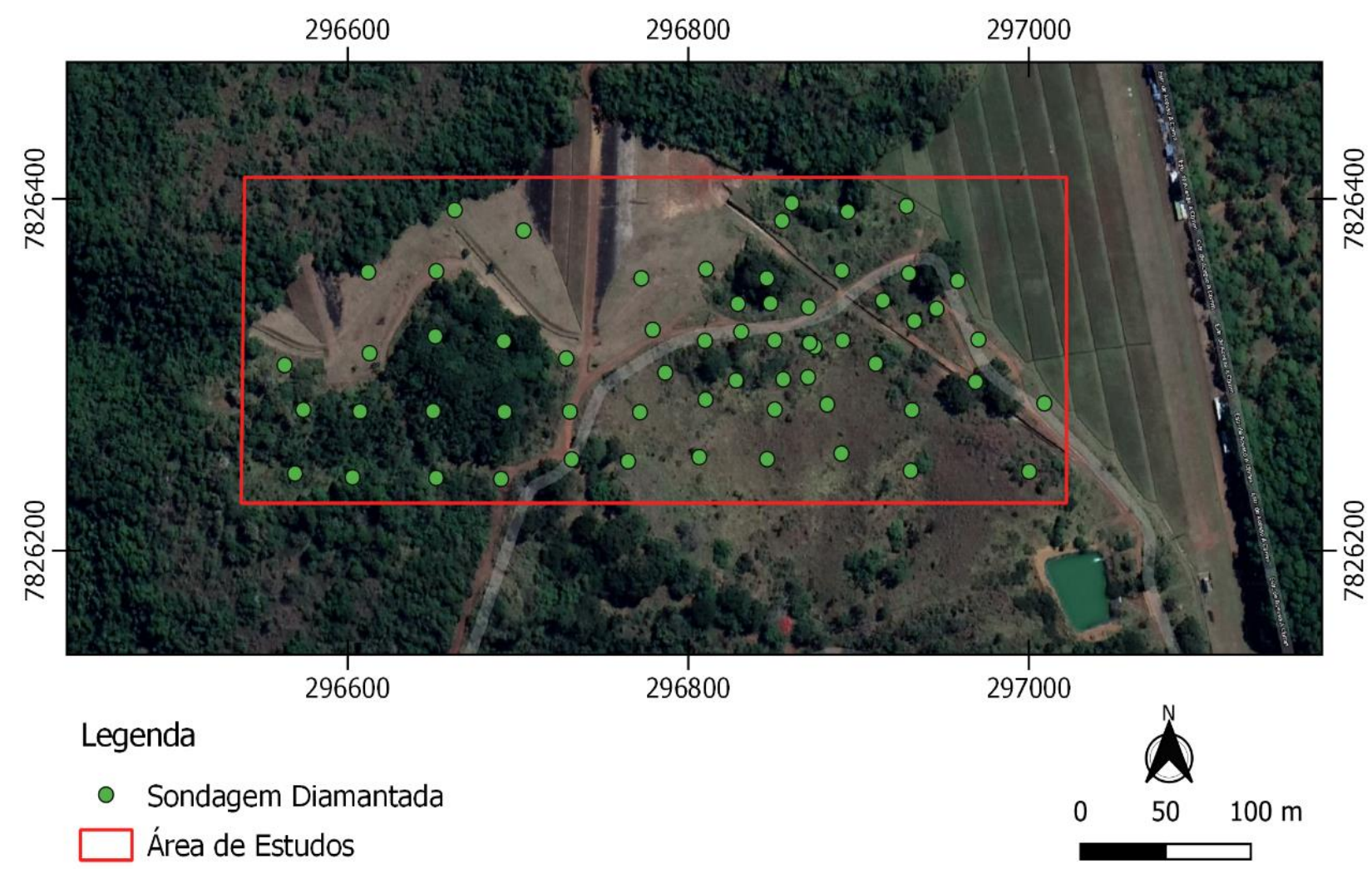

Figura 6 - Mapa com a localização dos furos de sondagem diamantada utilizados nesse trabalho, na área do depósito.

O processo utiliza as médias ponderadas dos teores das amostras divididas pelo comprimento. Desta forma, tentou-se regularizar as amostras em $1 \mathrm{~m}$, desde que o contato entre as unidades fosse respeitado.

Após a regularização, um total de 3282 amostras foram geradas (de um total de 3443), sendo que a média dos valores de espessura subiu de $0,93 \mathrm{~m}$ para $1,0 \mathrm{~m} \quad \mathrm{e} \quad \mathrm{a}$ variância, consequentemente, diminuiu, passando de 0,074 para 0,001. Os dados estatísticos podem ser visualizados na tabela 1 . 
Tabela 1 - Estatísticas descritivas para os valores de comprimento (em metros) das amostras dos testemunhos de sondagem.

\begin{tabular}{c|c|c}
\hline \multirow{2}{*}{ Estatística } & \multicolumn{2}{|c}{ Comprimento das amostras } \\
& Or) \\
\hline Número de amostras & 3443 & 3282 \\
\hline Mínimo & 0,100 & 0,750 \\
\hline Máximo & 4,710 & 1,440 \\
\hline Média & 0,930 & 1,000 \\
\hline Mediana & 0,871 & 0,990 \\
\hline Primeiro Quartil & 0,990 & 0,993 \\
\hline Terceiro Quartil & 1,000 & 1,008 \\
\hline Variância & 0,074 & 0,001 \\
\hline Desvio Padrão & 0,273 & 0,031 \\
\hline Coeficiente de & 0,293 & 0,031 \\
Variação & &
\end{tabular}

A análise estatística básica foi realizada para os teores de TREO (\%) para as amostras originais e para as amostras regularizadas. Para esse cálculo, foram consideradas todas as amostras do depósito, sem distinção por unidades. O objetivo dessa análise foi avaliar a variância entre os grupos de dados e possíveis discrepâncias durante a regularização. $\mathrm{O}$ resultado pode ser visualizado na tabela 2 .

O diagrama de frequências (Figura 7) para os teores de TREO (\%) do depósito é unimodal, assimétrico positivo.
Mostrando que a maior frequência de teores se encontra abaixo de $6 \%$ (75\% das amostras).

O histograma é típico de uma distribuição lognormal, encontrado em depósitos de metais raros, em que há um maior número de amostras com teores baixos e poucas amostras com teores altos (Yamamoto et al. 2001).

Tabela 2 - Estatísticas descritivas para os valores de TREO (\%) entre as amostras originais e as regularizadas.

\begin{tabular}{c|c|c}
\hline \multirow{2}{*}{ Estatística } & \multicolumn{2}{|c}{ Amostras - TREO } \\
\cline { 2 - 3 } & Originais & Regularizadas \\
\hline Número de amostras & 3443 & 3282 \\
\hline Mínimo & 0,021 & 0,381 \\
\hline Máximo & 32,980 & 31,976 \\
\hline Média & 5,063 & 5,072 \\
\hline Mediana & 4,091 & 4,195 \\
\hline Primeiro Quartil & 2,752 & 2,884 \\
\hline Terceiro Quartil & 6,157 & 6,031 \\
\hline Variância & 13,630 & 12,474 \\
\hline Desvio Padrão & 3,692 & 3,532 \\
\hline Coeficiente de Variação & 0,729 & 0,696 \\
\hline
\end{tabular}

A alta variabilidade dos teores de ETR dentro do depósito é constatada pelo valor da variância $(12,474)$, mesmo suavizada após a regularização.

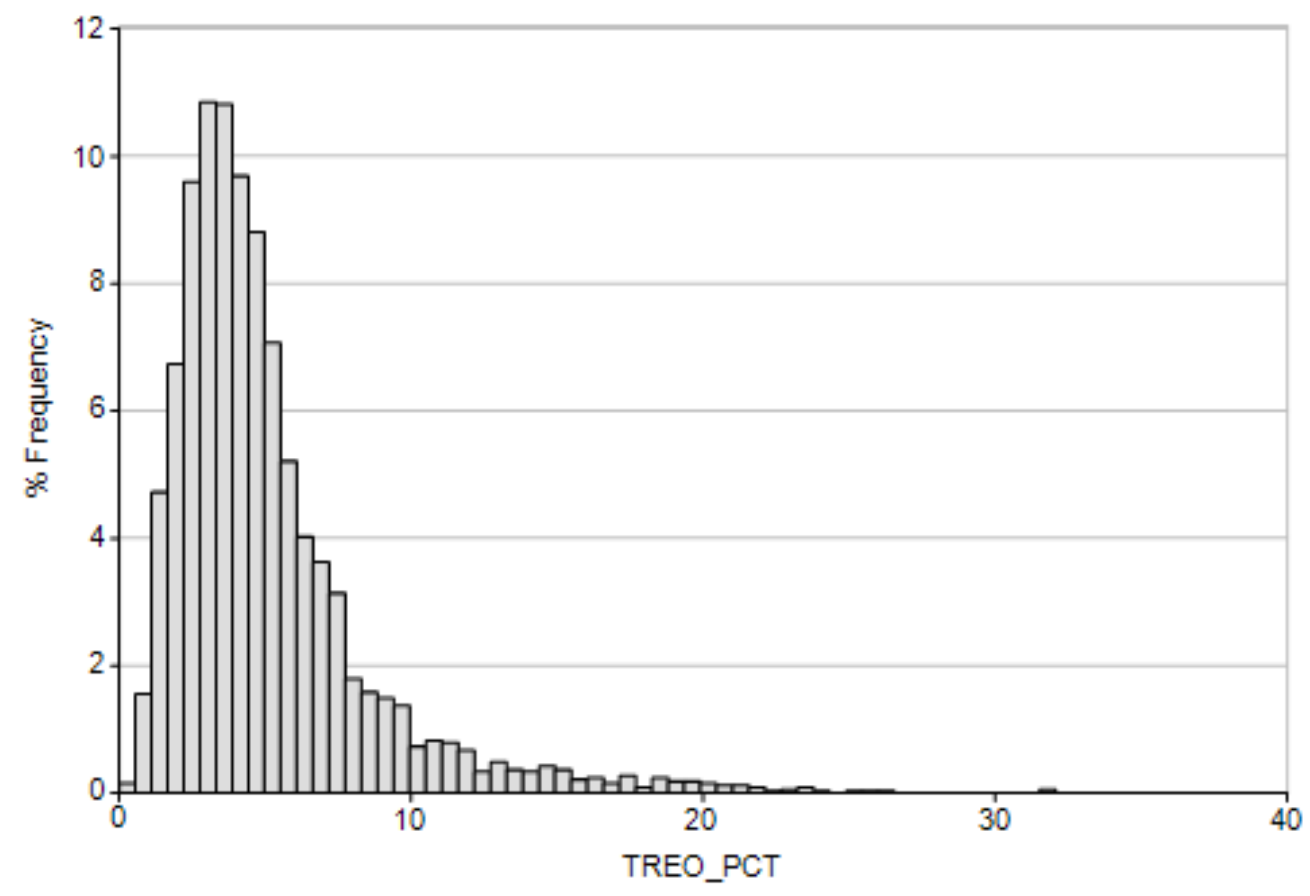

Figura 7 - Histograma dos teores de TREO (\%) após a regularização das amostras.

\section{Variografia}

A continuidade espacial dos valores de TREO

foi avaliada por meio da variografia. Os variogramas foram construídos utilizando o software SGeMS. Na primeira etapa foram utilizados os dados obtidos após regularização do 
comprimento de amostra para os processos variográficos. $\mathrm{O}$ variograma omnidirecional foi construído para identificar possíveis estruturas (anisotropia), utilizando os parâmetros que estão discriminados na tabela 3 . O variograma experimental, ajustado no modelo esférico pode ser visualizado na figura 8 .

Tabela 3 - Parâmetros para o cálculo dos variogramas omnidirecionais para a variável TREO.

\section{Parâmetros Variograma Omnidirecional}

\begin{tabular}{c|c}
\hline Número de Passos & 40 \\
\hline Separação do Passo & 10 \\
\hline Tolerância do Passo & 0,1 \\
\hline
\end{tabular}

A análise do variograma omnidirecional permitiu que se identificasse uma estruturação nos dados e, para que a direção de maior continuidade fosse encontrada, foram confeccionados variogramas em 9 direções.
Os parâmetros utilizados encontram-se na tabela 4.

A direção de maior continuidade para as amostras foi a de Azimute $67,5^{\circ}$ e Mergulho $0^{\circ}$, como pode ser verificado na figura 9 .

Adotou-se a direção perpendicular $157,5^{\circ}$ como a direção de menor continuidade (Figura 10), já que foi a única onde o variograma pode ser ajustado.

O variograma para a direção vertical encontrase na figura 11.

Com o intuito de melhorar a análise variográfica e, consequentemente, definir uma melhor estruturação das amostras, optou-se pelo estudo dos outliers.

Como os mesmos aumentam a dispersão dos dados em torno da média, contribuindo para o aumento da variância, os valores que se encontravam entre \pm duas vezes o valor do desvio padrão sobre a média foram substituídos.

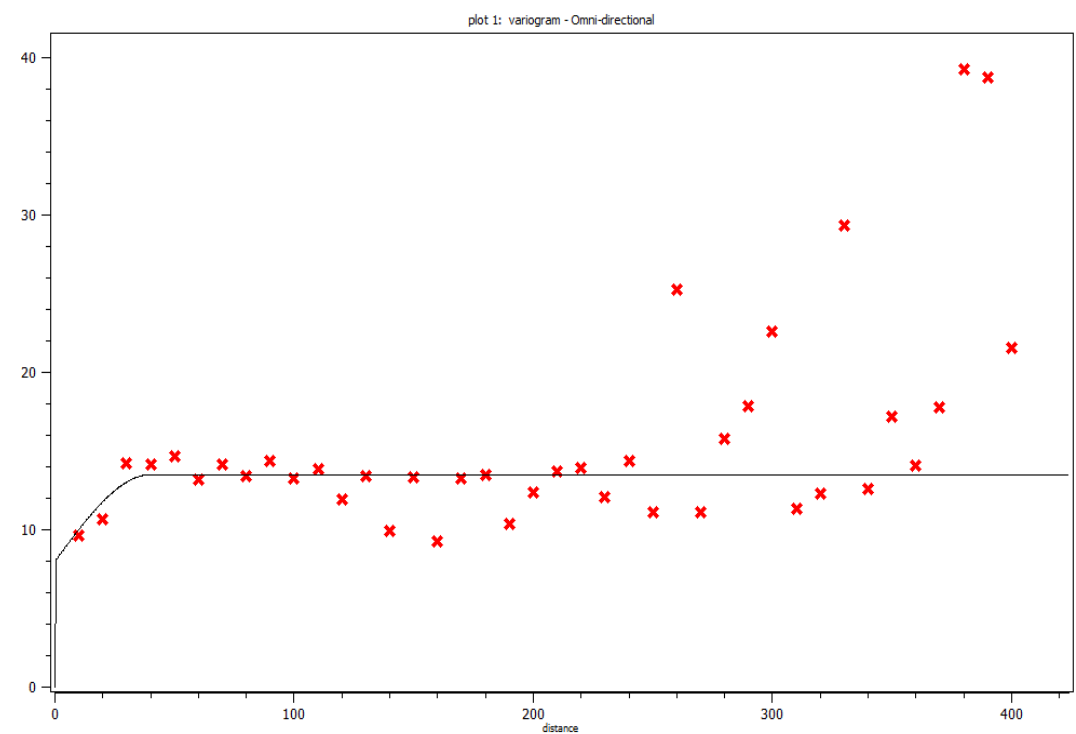

Figura 8 - Variograma omnidirecional para os teores de TREO (\%). Efeito pepita: 8; Patamar: 13; Amplitude: 40.

Tabela 4 - Parâmetros para o cálculo dos variogramas direcionais para as os teores de TREO (\%).

\section{Parâmetros Variograma}

\begin{tabular}{c|c|c|c|c|c}
\hline Azimute/Mergulho & $\begin{array}{c}\text { Número de } \\
\text { Passos }\end{array}$ & $\begin{array}{c}\text { Separação do } \\
\text { Passo }\end{array}$ & $\begin{array}{c}\text { Tolerância do } \\
\text { Passo }\end{array}$ & $\begin{array}{c}\text { Tolerância } \\
\text { Angular }\end{array}$ & $\begin{array}{c}\text { Largura da } \\
\text { Banda }\end{array}$ \\
\hline $0 / 0$ & 30 & 10 & 0,1 & 22,5 & 10 \\
\hline $22,5 / 0$ & 30 & 10 & 0,1 & 22,5 & 10 \\
\hline $45 / 0$ & 30 & 10 & 0,1 & 22,5 & 10 \\
\hline $67,5 / 0$ & 30 & 10 & 0,1 & 22,5 & 10 \\
\hline $90 / 0$ & 30 & 10 & 0,1 & 22,5 & 10 \\
\hline $112,5 / 0$ & 30 & 10 & 0,1 & 22,5 & 10 \\
\hline $135 / 0$ & 30 & 10 & 0,1 & 22,5 & 10 \\
\hline $157,5 / 0$ & 30 & 10 & 0,1 & 22,5 & 10 \\
\hline $0 / 90$ & 20 & 2 & 0,1 & 5 & 2 \\
\hline
\end{tabular}




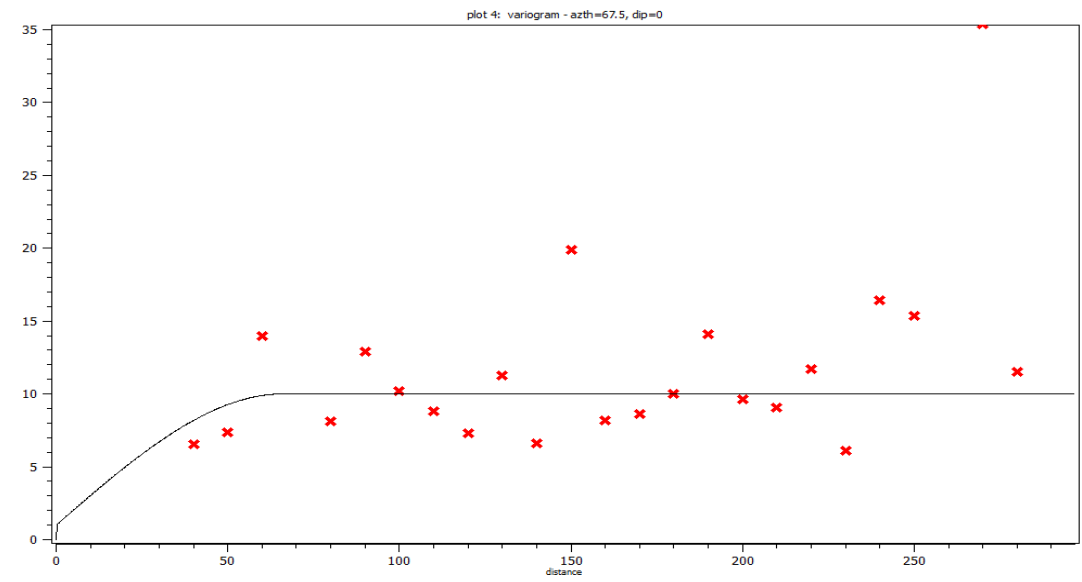

Figura 9 - Variograma direcional (67,5/0) para os teores de TREO. Efeito pepita: 1; Patamar: 10; Amplitude: 66.

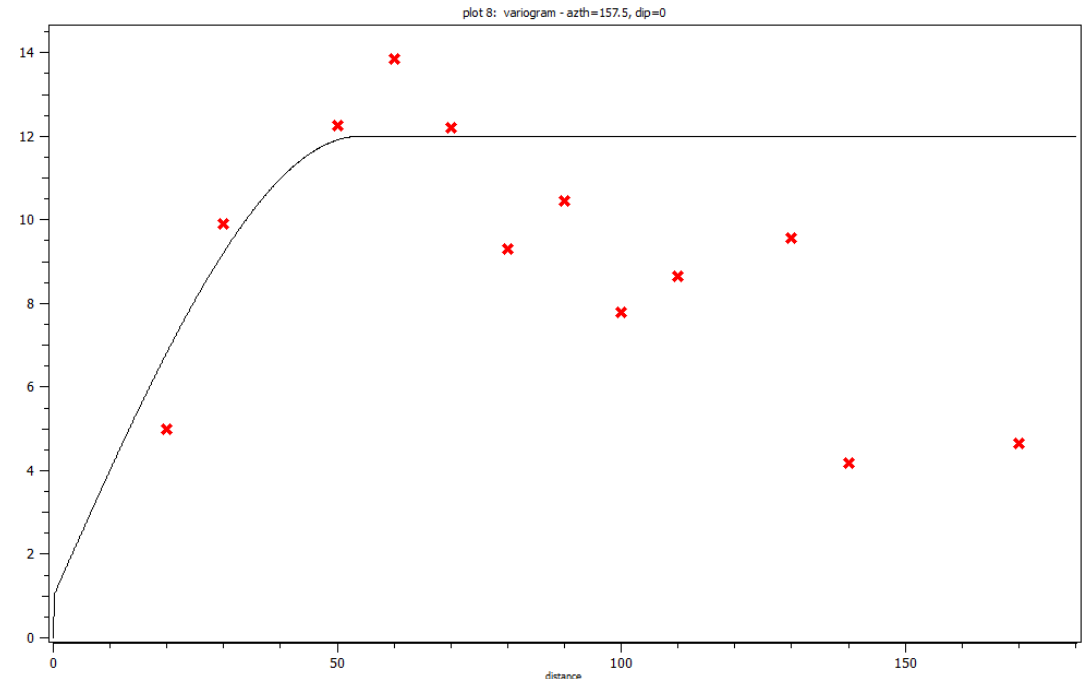

Figura 10 - Variograma direcional (157,5/0) para os teores de TREO. Efeito pepita: 1; Patamar: 11; Amplitude: 52.

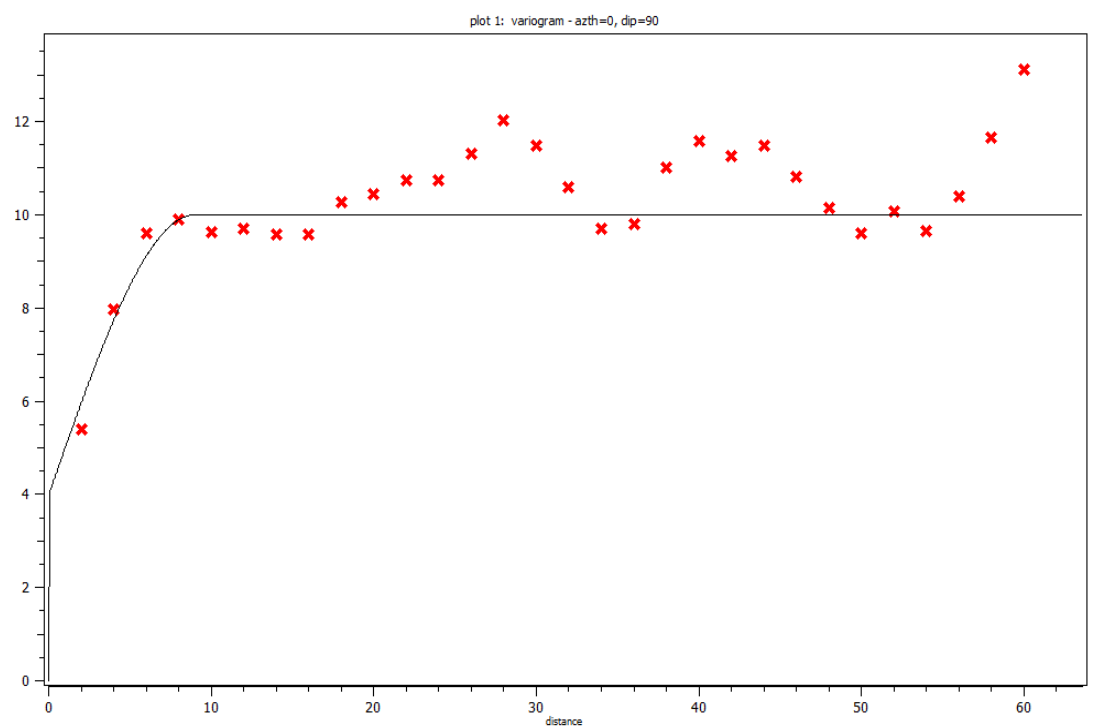

Figura 11 - Variograma vertical (0/90) para os teores de TREO ajustado no modelo esférico. Efeito pepita: 4; Patamar: 10 e; Amplitude:9.

Para os dados duas vezes o desvio padrão abaixo da média, o limite estabelecido foi 0 .

Ocorreu a substituição dos outliers pelo valor de 12,136 de TREO (\%) (o valor máximo assumido é igual a média somada duas vezes o desvio padrão). A figura 12 exibe o histograma para as amostras com substituição dos outliers. Uma nova moda foi criada, definindo assim o histograma como bimodal. O resumo estatístico pode ser visualizado na tabela 5 . 


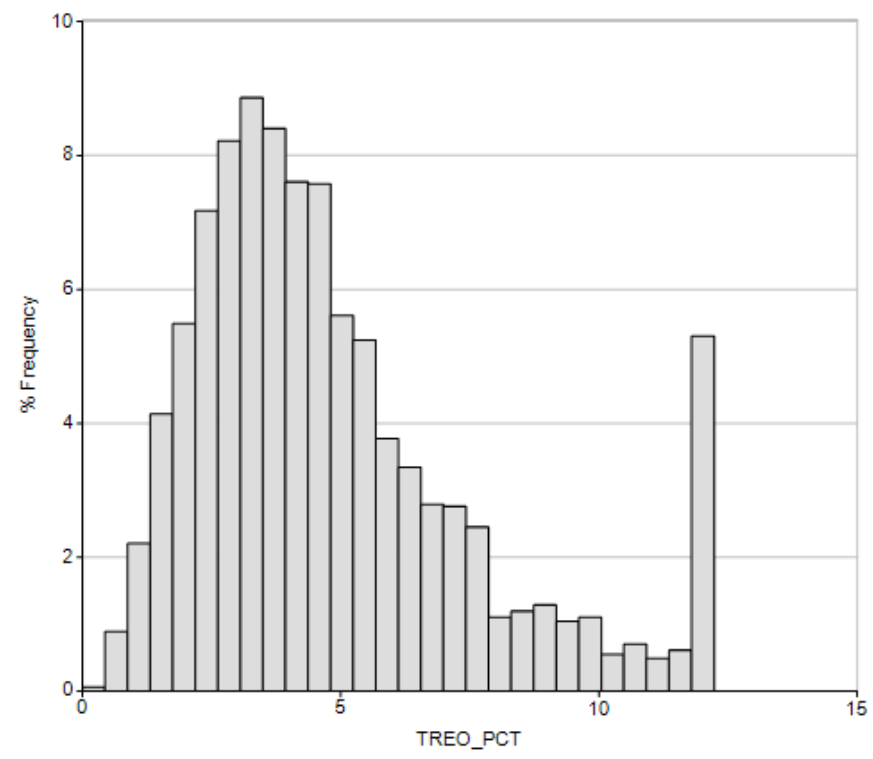

Figura 12 - Histograma dos teores de TREO (\%) para a população com outliers substituídos pelo valor da média + duas vezes o desvio padrão.

Tabela 5 - Estatísticas descritivas para os valores de TREO (\%) para as amostras com outliers substituídos.

\begin{tabular}{c|c}
\hline Estatística & Substituição dos outliers \\
\hline Número de amostras & 3282 \\
\hline Mínimo & 0,381 \\
\hline Máximo & 12,136 \\
\hline Média & 4,864 \\
\hline Mediana & 4,143 \\
\hline Primeiro Quartil & 2,884 \\
\hline Terceiro Quartil & 6,069 \\
\hline Variância & 7,751 \\
\hline Desvio Padrão & 2,784 \\
\hline Coeficiente de Variação & 0,572
\end{tabular}

O variograma omnidirecional para os dados com substituição dos outliers (Figura 13) se apresentou melhor estruturado do que o gerado para as amostras originais regularizadas (Figura 8). A amplitude aumentou 20 metros com diminuição do efeito pepita.

A direção de maior continuidade foi definida para a direção 22,5/0 (Figura 14) ao contrário da direção 67,5/0 previamente estabelecida (Figura 9). Para essa análise, a direção 67,5/0 não apresentou nenhuma estruturação, estabelecendo aleatoriedade nos dados. A direção de menor continuidade foi a mesma estabelecida para as amostras originais regularizadas $(157,5 / 0)$ (Figura 15).

O variograma vertical (0/90) apresentou melhor estruturação, como pode ser visualizado na figura 16. Em relação ao previamente modelado (amostras originais regularizadas) houve um incremento da amplitude passando de 9 para 21 metros e diminuição do efeito pepita de 4 para 3,2 .

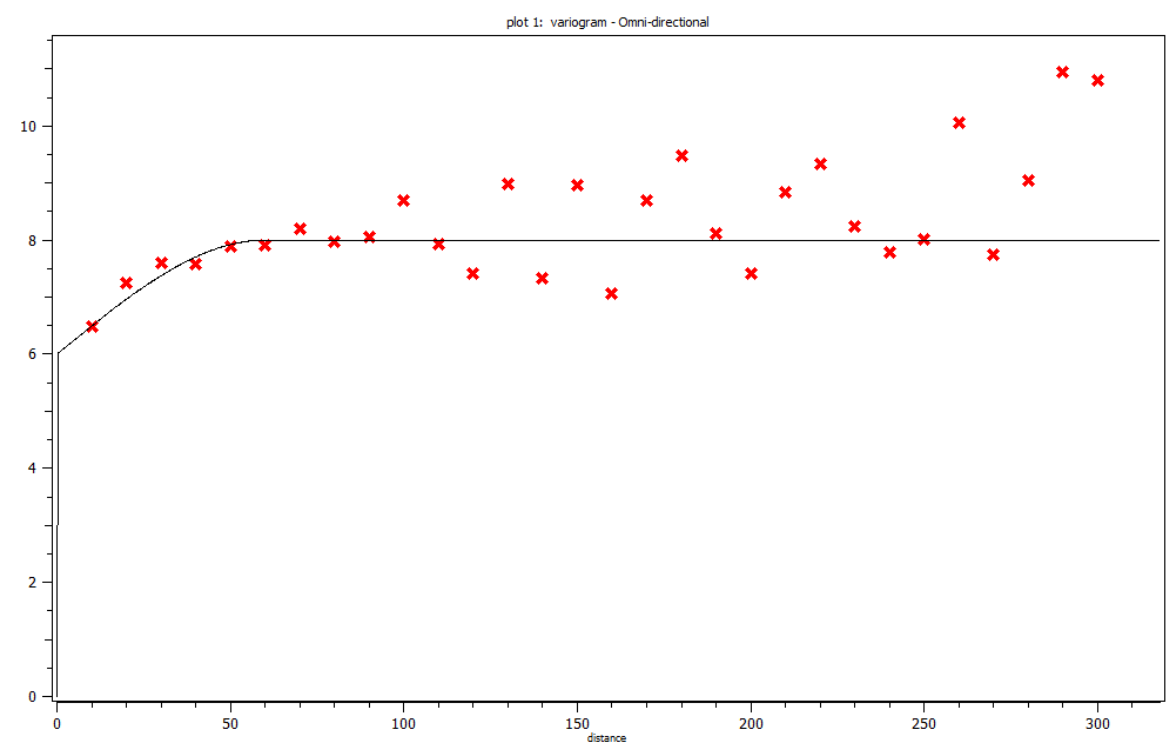

Figura 13 - Variograma omnidirecional para os teores de TREO (\%) com substituição dos outliers ajustado no modelo esférico. Efeito pepita: 6; Patamar: 8 e; Amplitude:60. 


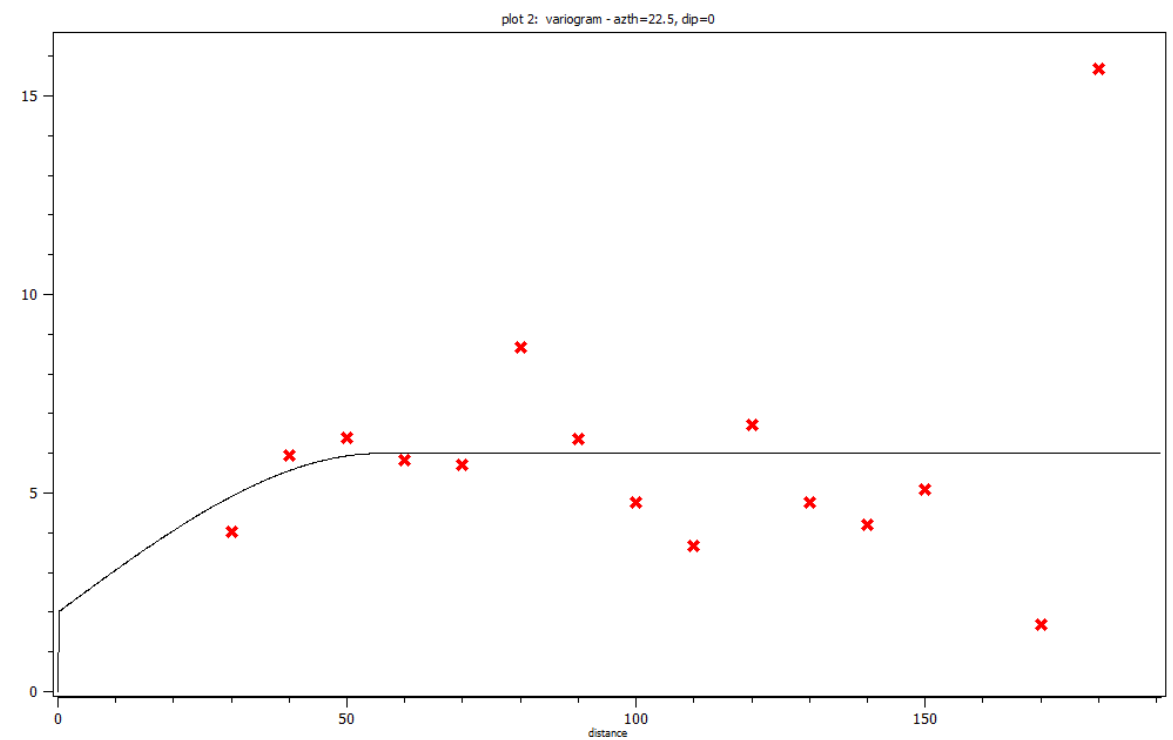

Figura 14 - Variograma direcional $(22,5 / 0)$ para os teores de TREO com substituição dos outliers ajustado no modelo esférico. Efeito pepita: 2; Patamar: 6; Amplitude: 51.

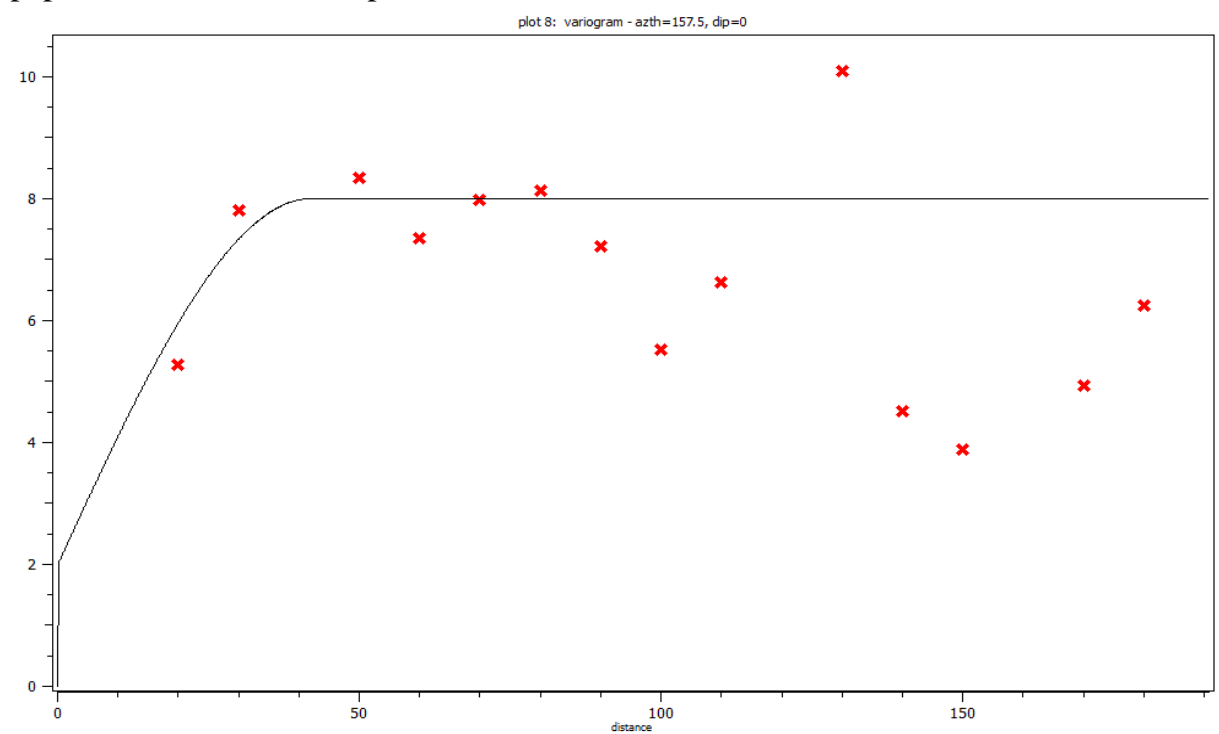

Figura 15 - Variograma direcional $(157,5 / 0)$ para os teores de TREO com substituição dos outliers ajustado no modelo esférico. Efeito pepita: 2; Patamar: 8; Amplitude: 42.

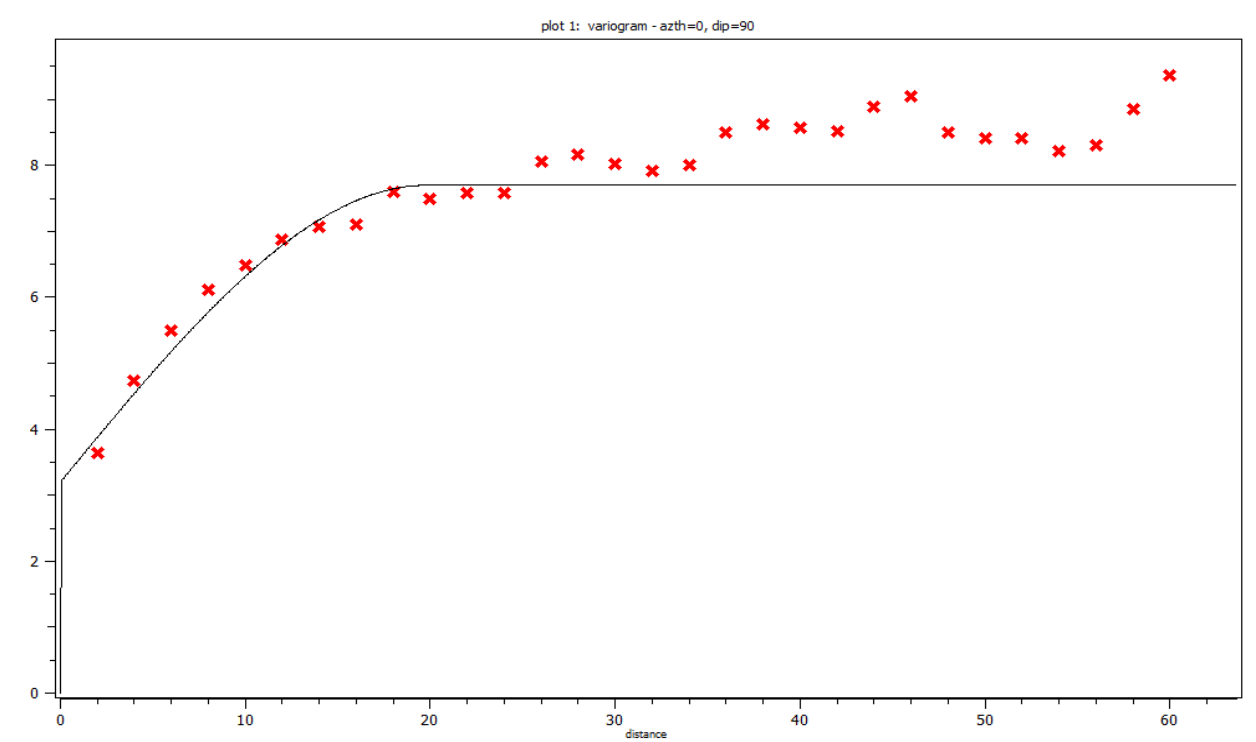

Figura 16 - Variograma vertical (0/90) para os teores de TREO com substituição dos outliers ajustado no modelo esférico. Efeito pepita: 3,2; Patamar: 7,7 e; Amplitude: 21. 
A comparação entre as propriedades dos variogramas gerados para as amostras originais regularizadas e as amostras com substituição dos valores dos outliers encontra-se na tabela 6. De maneira geral, os variogramas para as amostras após a substituição dos outliers foram melhor ajustados, e esses dados serão utilizados para a próxima etapa: estimativa de recursos.

Tabela 6 - Tabela comparativa entre as propriedades dos variogramas entre as amostras regularizadas e as com substituição dos outliers.

\begin{tabular}{c|c|c|c|c}
\hline \multirow{2}{*}{ Amostras } & \multirow{2}{*}{ Variogramas } & \multicolumn{2}{c}{ Propriedades dos Variogramas } \\
\cline { 2 - 5 } & & Efeito Pepita & Patamar & Amplitude \\
\hline \multirow{4}{*}{ Originais Regularizadas } & Omnidirecional & 8 & 13 & 40 \\
\cline { 2 - 5 } & Maior continuidade (67,5/0) & 1 & 10 & 66 \\
\cline { 2 - 5 } & Menor continuidade (157,5/0) & 1 & 11 & 52 \\
\cline { 2 - 5 } & Vertical (90/0) & 4 & 10 & 9 \\
\hline \multirow{4}{*}{ Substituição dos outliers } & Omnidirecional & 6 & 8 & 60 \\
\cline { 2 - 5 } & Maior continuidade (22,5/0) & 2 & 6 & 51 \\
\cline { 2 - 5 } & Menor continuidade (157,5/0) & 2 & 8 & 42 \\
\cline { 2 - 5 } & Vertical (90/0) & 3,2 & 7,7 & 21 \\
\hline
\end{tabular}

\section{ESTIMATIVA DE RECURSOS}

Antes de efetuar os cálculos para avaliação de recursos, aplicando o método de estimativa escolhido (krigagem ordinária), um modelo de blocos foi construído. O tamanho das células do modelo pode ser definido através do espaçamento entre furos, métodos de lavra e estruturas geológicas. A tabela 7 exibe os parâmetros utilizados nesse trabalho.

Tabela 7 - Dados utilizados para a construção do modelo de blocos.

\begin{tabular}{c|c|c|c}
\hline Coordenadas & $\mathbf{X}$ & Y & Z \\
\hline Máximo & 297028 & 7826400 & 1120 \\
\hline Mínimo & 296537 & 7826240 & 875 \\
\hline Distância & 491 & 160 & 245 \\
\hline Tamanho da Célula & 10 & 10 & 3 \\
\hline Quantidade de células & 49 & 16 & 82 \\
\hline
\end{tabular}

Definiu-se o tamanho do bloco de $10 \mathrm{~m}$ x 10 $\mathrm{m} \times 3 \mathrm{~m}$, totalizando um total de 49 blocos na direção X, 16 blocos na direção Y e 82 blocos na direção Z.

A caixa criada, que será preenchida pelos blocos, englobando a área do depósito, pode ser visualizada na figura 17.

O tamanho definido na tabela 6 será o tamanho máximo que a célula (ou bloco) poderá assumir, porém como o contato geológico será preservado e, até mesmo, o limite da superfície topográfica, subcélulas serão criadas

Os blocos de tamanho máximo são divididos para se enquadrar às formas dos corpos mineralizados. Com a conclusão do modelo de blocos e a definição dos parâmetros do variograma (Tabela 6), o elipsoide de busca foi construído.

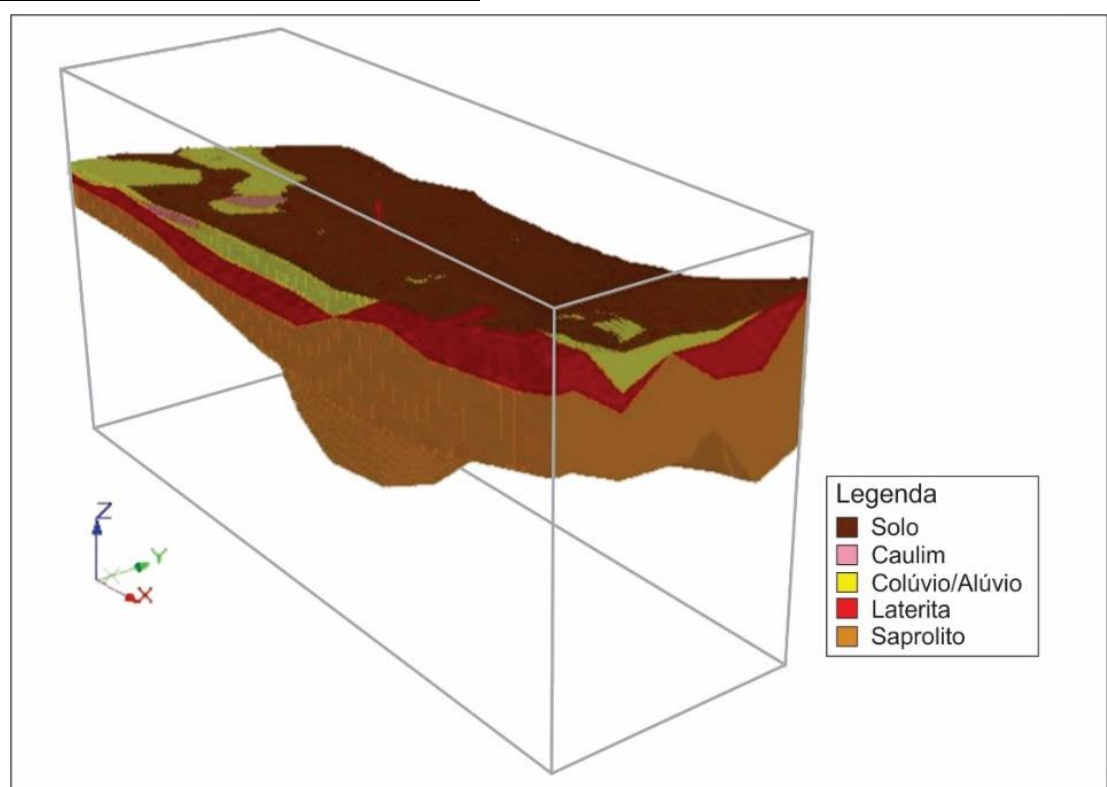

Figura 17 - Relação entre a caixa limite do modelo de blocos com o modelo tridimensional do depósito. O eixo Y indica o Norte. 
Mesmo o variograma indicando uma direção de continuidade de 51 metros (direção 22,5/0) e 60 metros (omnidirecional) definiu-se que o maior raio de busca do elipsoide seria de 45 metros na direção $\mathrm{Y}$, com o objetivo de realizar uma modelagem mais conservadora e robusta. $\mathrm{O}$ elipsoide de busca utilizado foi rotacionado $22,5^{\circ}$ no eixo $\mathrm{Y}$, o eixo $\mathrm{X}$ apresentando raio de busca de $30 \mathrm{~m}$ e $\mathrm{Z}$ com raio de busca de até $14 \mathrm{~m}$.

Com os parâmetros definidos (variografia e elipsoide), a krigagem ordinária foi aplicada para a estimativa de recursos do Depósito de Terras
Raras Área Zero. O modelo tridimensional estimado encontra- se ilustrado na figura 18.

A figura 19 mostra uma seção geológica em que se pode constatar que os maiores valores de TREO se encontram na unidade colúvio/alúvio, nas porções superficiais do modelo e em algumas porções saprolíticas.

Os resultados da avaliação de recursos encontram-se na tabela 8 .

Os recursos totais avaliados para o depósito são de 10,5 milhões de toneladas com teor de TREO de $4,75 \%$.

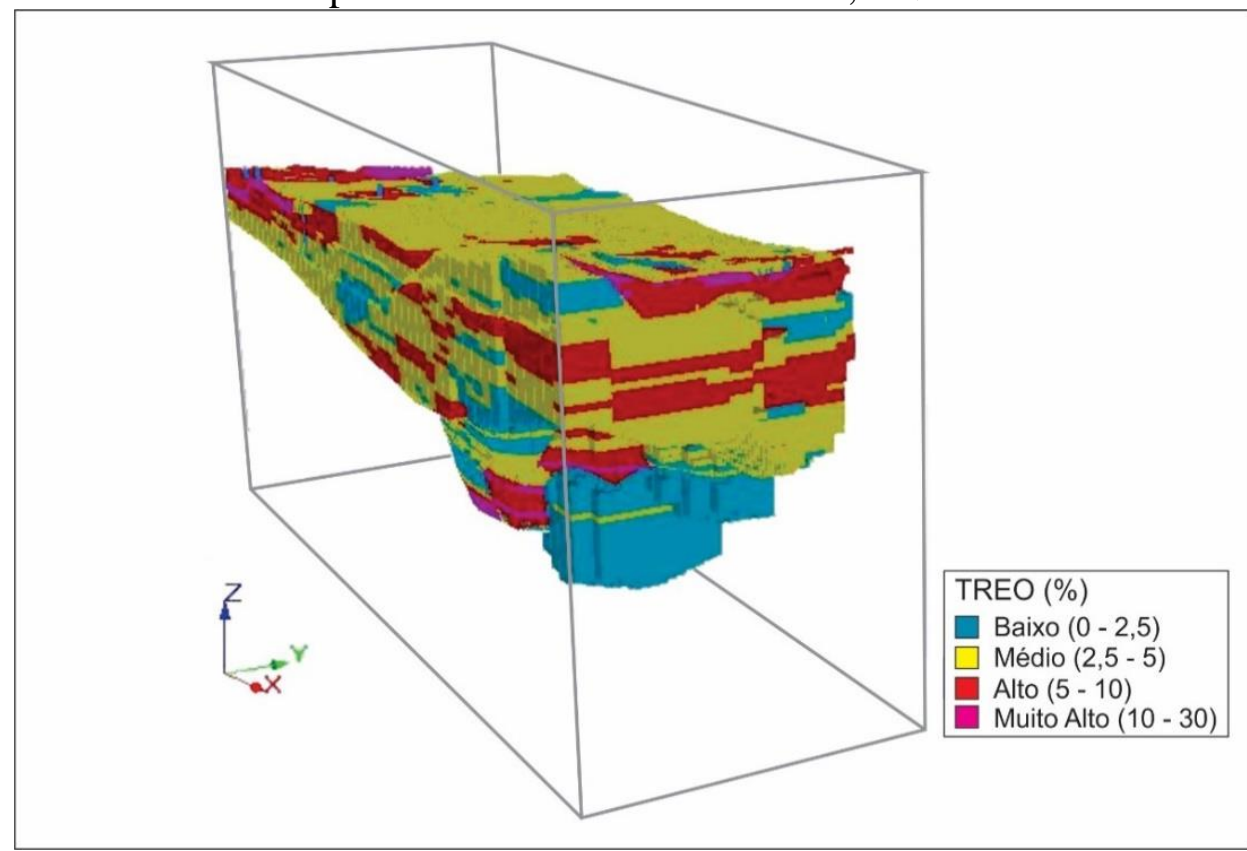

Figura 18 - Modelo de blocos exibindo o resultado da krigagem ordinária para os teores de TREO. O eixo Y indica o Norte.

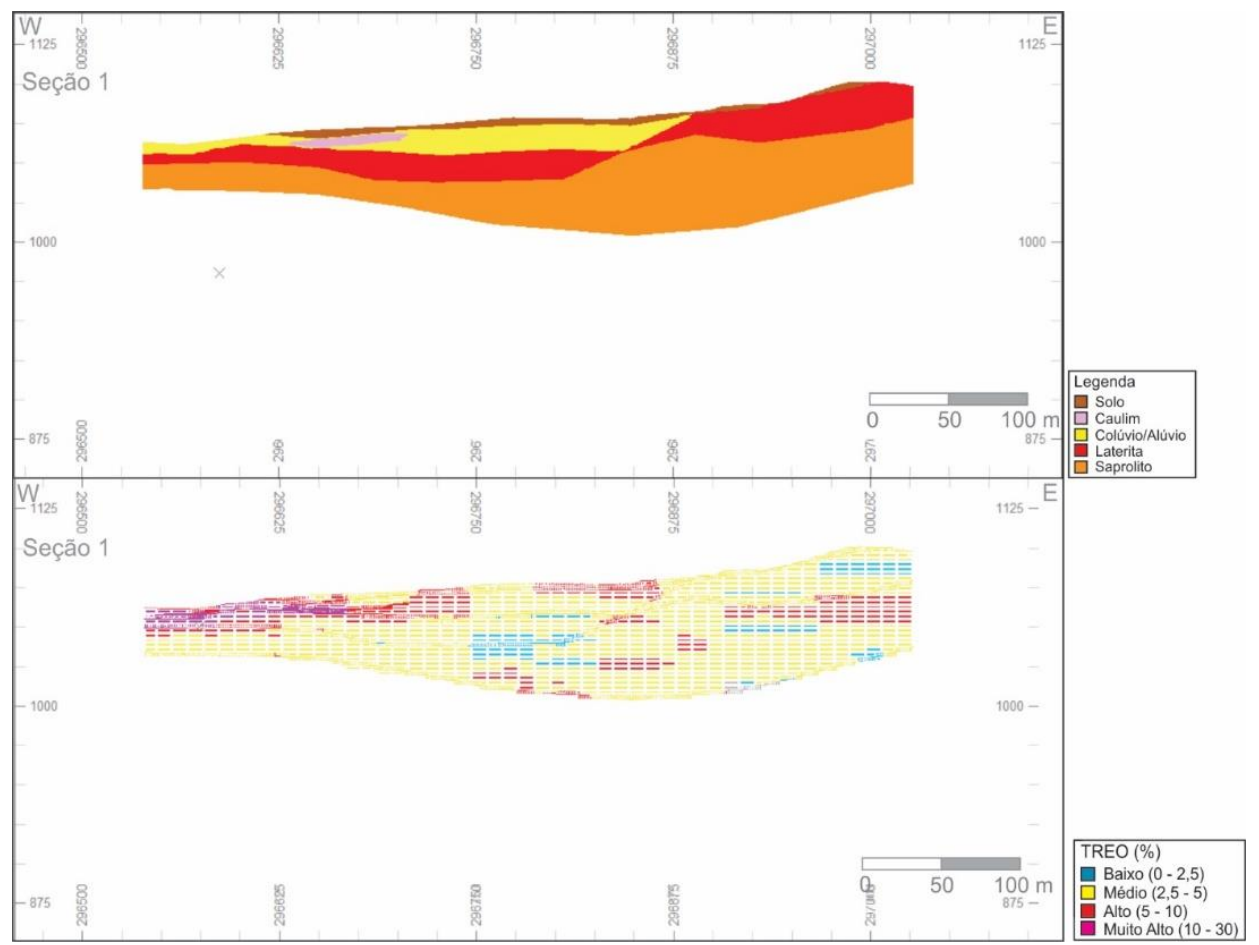

Figura 19 - Seção comparando o modelo geológico com o modelo de blocos com os teores de TREO (\%) estimados por krigagem ordinária. 
Tabela 8 - Recursos estimados para o Depósito de Terras Raras Área Zero.

\begin{tabular}{c|c|c|c}
\hline Litotipo & Tonelagem & Volume $\left(\mathbf{m}^{\mathbf{3}}\right)$ & Teor TREO $(\%)$ \\
\hline Solo & $319.463,52$ & $158.150,25$ & 3,59 \\
\hline Intervalo caulinítico & $182.423,28$ & $98.077,03$ & 4,70 \\
\hline Colúvio/Alúvio & $1.470 .024,95$ & $724.150,22$ & 7,37 \\
\hline Laterita & $1.713 .397,64$ & $682.628,54$ & 4,74 \\
\hline Saprolito & $6.815 .510,51$ & $3.495 .133,59$ & 4,25 \\
\hline Total & $\mathbf{1 0 . 5 0 0 . 8 1 9 , 9 0}$ & $\mathbf{5 . 1 5 8 . 1 3 9 , 6 3}$ & $\mathbf{4 , 7 5}$
\end{tabular}

\section{Validação da Krigagem}

Para a validação dos dados da krigagem, foi efetuada a comparação entre os dados de estatística descritiva estimados por krigagem ordinária e os dados para as amostras originais regularizadas (Tabela 9).

Além dos dados estatísticos analisou-se a distribuição dos dados no diagrama de frequências (Figura 20).

A média de TREO aumentou de 5,072\% para $5,272 \%$ nos dados estimados por krigagem ordinária, não ocasionando grandes variações para a estimativa. A variância diminuiu de 12,474 para 10,998 evidenciando uma leve suavização dos dados, o que já é esperado para a krigagem ordinária.

O histograma apresenta o mesmo comportamento encontrado nas amostras originais regularizadas (Figura 7), sendo unimodal, assimétrico positivo configurando uma distribuição lognormal.

Dessa forma, define-se que o processo de estimativa foi satisfatório para o depósito analisado.

Tabela 9 - Comparação entre os dados estatísticos para teores de TREO (\%) das amostras originais regularizadas e blocos estimados por krigagem ordinária.

\begin{tabular}{c|c|c}
\hline \multirow{2}{*}{ Estatística } & Amostras & Modelo de Blocos \\
\cline { 2 - 3 } & Regularizadas & Krigagem Ordinária \\
\hline Número de amostras/ Número de blocos & 3282 & 422461 \\
\hline Mínimo & 0,381 & 0,431 \\
\hline Máximo & 31,976 & 25,554 \\
\hline Média & 5,072 & 5,272 \\
\hline Mediana & 4,195 & 4,415 \\
\hline Primeiro Quartil & 2,884 & 3,013 \\
\hline Terceiro Quartil & 6,031 & 6,604 \\
\hline Variância & 12,474 & 10,998 \\
\hline Desvio Padrão & 3,532 & 3,316 \\
\hline Coeficiente de Variação & 0,696 & 0,629
\end{tabular}

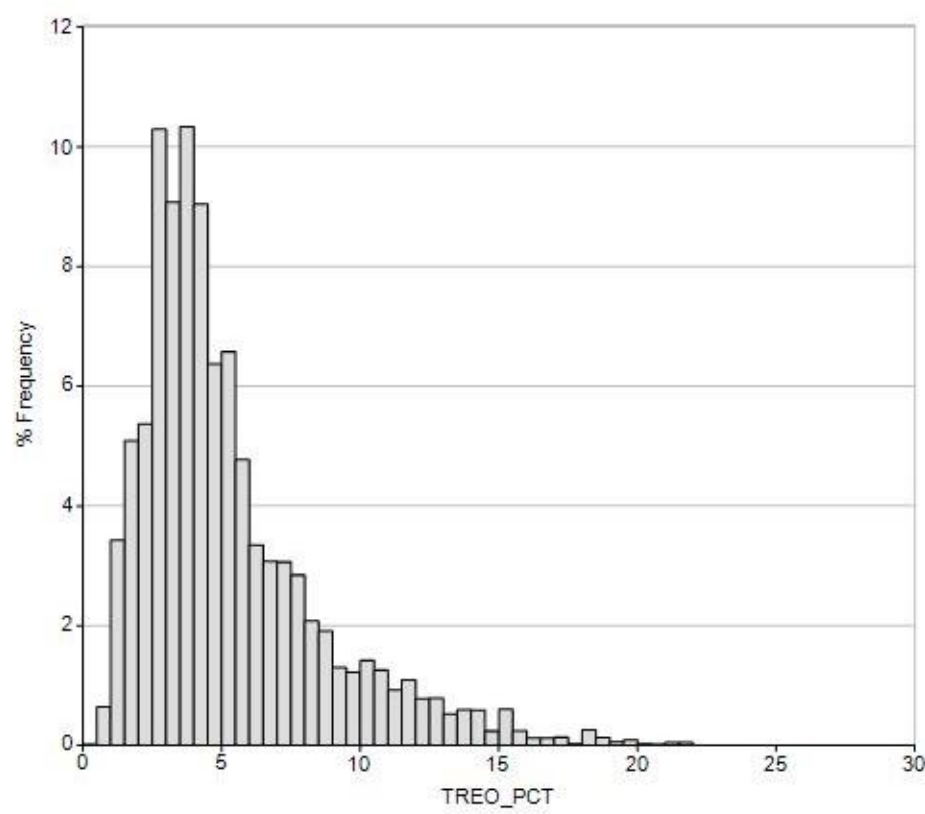

Figura 20: Histograma dos teores de TREO (\%) para os blocos estimados por krigagem ordinária. 


\section{Curva Tonelagem x Teor}

A curva de tonelagem $\mathrm{x}$ teor, também chamada de curva de parametrização, é uma importante ferramenta que permite a determinação da vida útil do empreendimento mineiro. Através dessa curva, pode-se obter, utilizando diferentes teores de corte, a tonelagem do depósito.

A figura 21 mostra a curva de parametrização para o Depósito Área Zero.

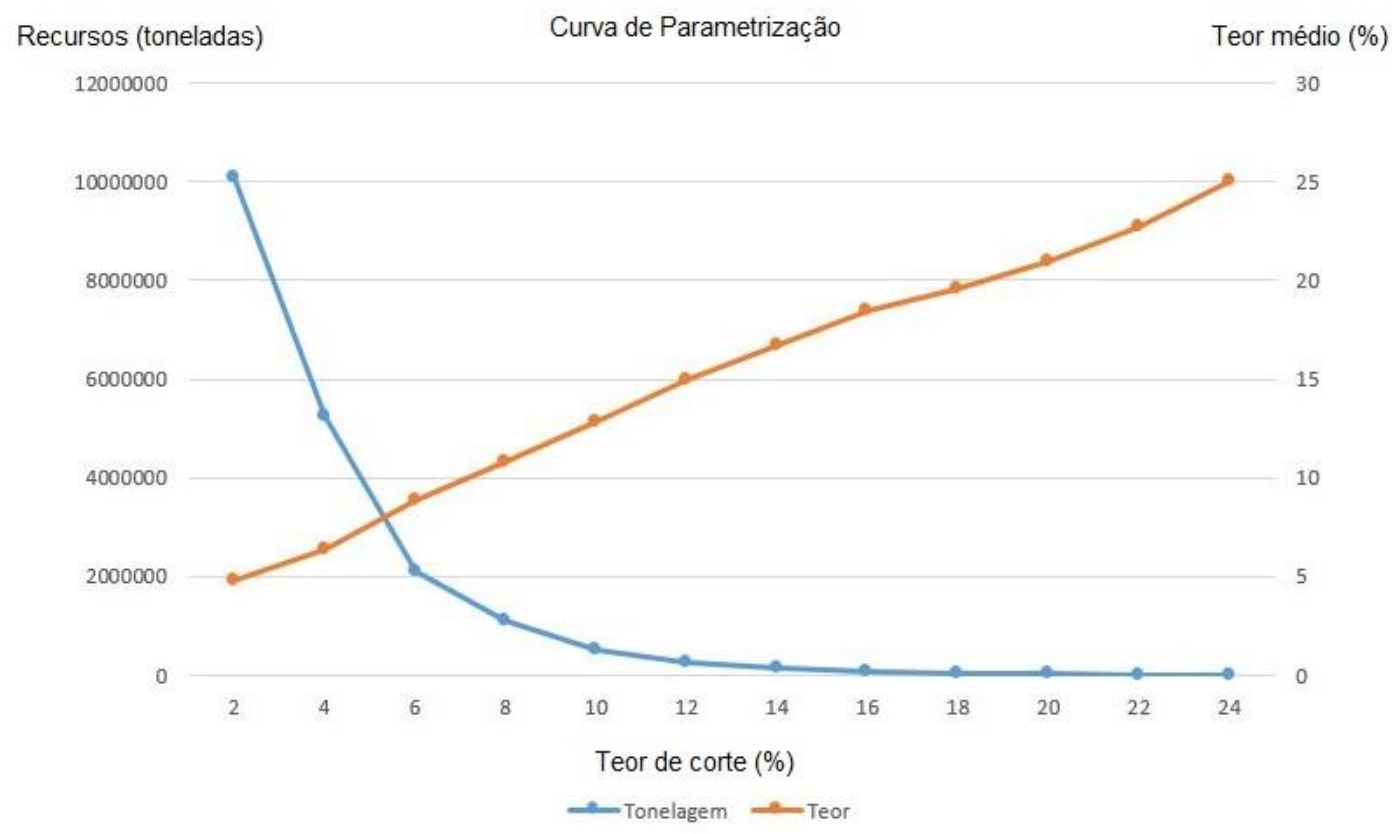

Figura 21: Curva de parametrização para o Depósito Área Zero.

\section{CONCLUSÕES}

A análise estatística, posteriormente confirmada pela krigagem ordinária, indicou que todas as unidades descritas para o depósito estão mineralizadas. Do topo para a base encontram-se o solo com teor médio de 3,59\% de TREO, o intervalo caulinítico, muitas vezes referido como caulim, com 4,70 \% de TREO, a unidade colúvio/alúvio com 7,37 \% de TREO, a laterita com 4,74\% de TREO e o saprolito (alteração do carbonatito) com 4,25\% de TREO. Esses teores foram definidos a partir da krigagem ordinária. Optou-se por não estimar os valores de carbonatito (rocha inalterada) por se encontrar apenas em dois furos de sondagem, porém a análise estatística das amostras definiu um teor médio de $1,41 \%$ de TREO.

Os ETR no depósito apresentam alta variabilidade, configurando uma distribuição lognormal, com muitos dados com teores baixos e poucos dados com valores altos. Devido a esse aspecto a variografia foi dificultada, com muitos variogramas configurando aleatoriedade, ou seja, efeito pepita puro. $\mathrm{O}$ método de substituição dos outliers pelo valor da média +2 vezes o desvio padrão, diminuiu a variabilidade dos dados, suavizando-os e permitindo o melhor ajuste dos variogramas que foram utilizados para a estimativa de recursos.

A análise dos variogramas experimentais, ajustados no modelo esférico, permitiu que a direção de maior continuidade fosse determinada, sendo ela a de azimute $22,5^{\circ} \mathrm{com}$ as amostras estruturadas até um alcance de 51 metros. O alcance definido é maior do que a malha de sondagem $(\sim 30 \mathrm{~m})$ proporcionando confiabilidade na estimativa.

Para o depósito estudado, mesmo apresentando uma alta variabilidade de dados, a krigagem ordinária se mostrou um método eficiente para a modelagem e estimativa de recursos.

A tonelagem do total do depósito com um teor de corte de $0,4 \%$ é de 10,5 milhões de toneladas com um teor médio de $4,75 \%$ de TREO.

\section{AGRADECIMENTOS}

Os autores agradecem a empresa Itafós pela disponibilização dos dados de sondagem e à Coordenação de Aperfeiçoamento de Pessoal de Nível Superior pela bolsa de estudos do mestrado que originou esse artigo. 


\section{REFERÊNCIAS}

GIBSON, S.A.; THOMPSON, R.N.; DICKINA, P.; LEONARDOSO, H. High-Ti and low-Ti mafic potassic magmas: Key to plume-lithosphere interactions and continental flood-basalt genesis. Earth and Planetary Science Letters, v. 136. p. 149-165, 1995.

ISAAKS, E.H. \& SRIVASTAVA, R.M. Applied geoestatistics: introduction to applied geostatistics. Oxford University Press, New York, 1989. 561 p.

ISSA FILHO, A.; LIMA, P.R.A.S.; SOUZA, O.M. Aspectos da geologia do complexo carbonatítico do Barreiro, Araxá, MG, Brasil. In: CBMM, Complexos Carbonatíticos do Brasil: Geologia. São Paulo, CBMM,1984. p. 20-44.

JOURNEL, A.G. \& HUIJBREGTS, J.C.H. Mining geostatistics. New York: Academic Press, 1978, 600 p.

LAPIDO-LOUREIRO, F.E. \& SANTOS, R.L.C. Terras Raras no Brasil: Reservas, Características Químico-Mineralógicas de suas Ocorrências e Depósitos. In: O Brasil e a Reglobalização da Indústria de Terras Raras. CETEM/MCTI, Rio de Janeiro, Capítulo 2. p. 68-144, 2013.

NEWMANN, R. \& MEDEIROS, E.R. Comprehensive mineralogical and technological caracterisation of the Araxá (SE Brazil) complex REE (Nb-P) ore, and the fate of its processing. International Journal of Mineral Processing, v. 144. p. 1-10, 2015

SEER, H.J. Evolução Tectônica dos Grupos Araxá, Ibiá e Canastra na sinforma de Araxá, Minas Gerais. Brasília, 1999. 267 p. Tese (Doutorado). Instituto de Geociências. Universidade de Brasília.
SILVA, A.B. Jazida de nióbio de Araxá, Minas Gerais. In: SCHOBBENHAUS, C.; QUEIROZ, E.T.; COELHO, C.E.S. (Eds). Principais depósitos minerais brasileiros - ferro e metais da indústria do aço. MME/DNPM, Brasília, v. 2. p. 456-462, 1986.

TRAVERSA, G.; GOMES, C.B.; BROTZU, P.; BURAGLINI, N.; MORBIDELLI, L.; PRINCIPATO, M.S.; RONCA, S.; RUBERTI, E. Petrography and mineral chemistry of carbonatites and mica-rich rocks from the Araxá complex (Alto Paranaíba Province, Brazil). Anais da Academia Brasileira de Ciências, v. .73. p. 71-98, 2001.

VONCKEN, J.H.L. The Rare Earth Elements: An Introduction. Springer. 2016, 127 p.

WARING, M.H.; TEDESCO, M.A.; CARVALHO, M.S.; OLIVEIRA, A.S.D. A Geologia do Depósito de Fosfato e Terras Raras do Projeto Araxá - MbAC Fertilizantes. In: SIMPÓSIO BRASILEIRO DE METALOGENIA, III, Gramado, 2013. Atas...Gramado: CPRM, 2013.

YAMAMOTO, J.K. Análise geoestatística. In: Yamamoto, J.K. (org.). Avaliação e classificação de reservas minerais. São Paulo, Edusp, p. 69-92, 2001.

YAMAMOTO, J.K.; BETTENCOURT, J.S.; MONTANHEIRO, T.J. Análise estatística. In: Yamamoto, J.K. (org.). Avaliação e classificação de reservas minerais. São Paulo, Edusp, 2001. p. $49-68$.

Submetido em 28 de junho de 2019 Aceito para publicação em 20 de abril de 2020 